\title{
Triphenylamine and some of its derivatives as versatile building blocks
}

\section{for organic electronic applications}

Philippe Blanchard, ${ }^{\star a}$ Claudia Malacrida, ${ }^{b}$ Clément Cabanetos, ${ }^{\mathrm{a}}$ Jean Roncalia and Sabine Ludwigs ${ }^{* b}$

a Group Linear Conjugated Systems, MOLTECH-Anjou, CNRS UMR 6200, University of Angers, 2 Bd Lavoisier, 49045 Angers, France

b IPOC - Functional Polymers, Institute of Polymer Chemistry, University of Stuttgart, Pfaffenwaldring 55, 70569 Stuttgart, Germany

Corresponding authors: philippe.blanchard@univ-angers.fr; sabine.ludwigs@ipoc.unistuttgart.de

Keywords - triphenylamine, electrochemistry, crosslinking, push-pull molecules, organic solar cells, polymers

\begin{abstract}
:
This review article gives an overview of past and current activities in the Linear Conjugated Systems group of Angers and in the IPOC - Functional Polymers group of the Institute of Polymer Chemistry of Stuttgart on the use of triphenylamine (TPA) as versatile building block for organic electronics. In the first part, the properties of TPA itself are introduced including geometrical and energy level considerations. Dimerization of TPA to tetraphenylbenzidine (TPB) upon electrochemical oxidation is highlighted. The blocking of TPA para-positions and its implications in terms of electroactivity is further discussed. The second part shows that dimerization of TPA as pendant redox-active moieties in polymers is a versatile strategy to crosslink polymer films. Coming from redox homopolymers the crosslinking strategy is extended towards conjugated redox polymers based on polythiophenes and block copolymers. Conductivity mechanisms and the influence of doping level on conductivity is probed with cyclic voltammetry coupled with in-situ conductance and four point probe measurements. The last part is dedicated to the use of TPA as electron-donating block in the design of donor- $\pi$-acceptor chromophores and their use as active material in organic photovoltaics. An overview of some relevant TPA-based push-pull molecules from literature and our contribution to this field are presented emphasizing the progress of the photovoltaic performances of organic solar cells made over the last decade.
\end{abstract}




\section{Introduction}

Triphenylamine (TPA) derivatives are a class of versatile redox active molecules that have attracted particular attention in relation to their promising hole transport properties. $^{1-4}$ Applications include various thin layer opto-electronic devices ${ }^{1,5,6}$ comprising organic light emitting diodes (OLEDs), ${ }^{7,8}$ electrochromic devices, ${ }^{9}$ dye sensitized solar cells, organic solar cells (OSCs) $)^{10-12}$ and perovskite solar cells. ${ }^{12-14}$ The electron-rich character of TPA has also been exploited for electrochemical storage of energy ${ }^{15}$ and electrical memory devices. ${ }^{16,17}$ The use of TPA derivatives is particularly appealable due to a number of desirable properties, including their synthetic accessibility and the possibility of finely tuning their redox and absorption characteristics.

After an introduction on the structural and electronic properties of TPA, this review article will discuss, through some examples, the interest of TPA to trigger chemical or electrochemical couplings affording cross-linked electroactive and nanostructured polymer films. Then, an overview of push-pull molecules derived from TPA will be presented showing the interest of this major class of compounds as donor materials for organic photovoltaics (OPV) and the considerable progress achieved over the last decade.

In this context, the past and current research activities of our groups devoted to these fields will be emphasized. 


\section{Structural and electronic properties of TPA}

TPA is a tertiary amine bearing three aromatic groups. Because of the resonance delocalization of the electron lone pair on its entire molecular structure, TPA is characterized by a very low basicity compared to aliphatic amines.

Different synthetic ways for TPA-type molecules are known. They can for example be obtained by modifications of the Ullmann condensation reaction (1903) through the nucleophilic substitution of an aryl-halide in the presence of a copper catalyst and a base. ${ }^{18,19}$ More recently, the use of palladium catalysts with phosphine ligands was found to be a successful approach for the synthesis of TPA derivatives such as mixed secondary arylamines obtained from amination of aryl halides, ${ }^{20,21}$ allowing milder reaction conditions and easier separation and crystallization steps. For example, among several phosphine ligated palladium complexes, Buchwald et al. proposed the use of a catalytic system constituted of BINAP (2,2'-bis(diphenylphosphino)-1,1'-binaphthyl) and $\mathrm{Pd}_{2}\left(\mathrm{dba}_{3}\right)^{2 .}{ }^{21}$ Ironcatalyzed aromatic amination for synthesizing diaryl- and triarylamines has also been successfully developed..$^{22}$

The molecular geometry of TPA results from two opposing factors: the resonance stabilization of the m-electron systems and the steric repulsion of protons of neighboring phenyl rings (Figure 1b). ${ }^{4}$ A planar geometry (D3h symmetry) is favored to maximize the conjugation of the m-electron systems of the phenyl groups, on the other hand the steric repulsions are minimized through their tilting from the plane. These two factors lead to a propeller like structure (C3 symmetry). X-ray measurements and computational calculations agree for an average $\mathrm{C}-\mathrm{N}$ bond length of $1.42 \AA$, a $\mathrm{C}-\mathrm{N}-\mathrm{C}$ bond angle of $120^{\circ}$, and an optimum tilting of phenyl groups through a torsional angle of $42^{\circ}$ with respect to the CCCN plane..$^{4,23-25}$ 
a)<smiles>[R]c1ccc(N(c2ccc([R])cc2)c2ccc([R])cc2)cc1</smiles>

$\mathrm{R}:$ 1) $-\mathrm{H}$ (TPA)

2) $-\mathrm{NH}_{2}$

3) $-\mathrm{OCH} 3$

4) $-\mathrm{CH}_{3}(p-\mathrm{TTA})$

5) $-\mathrm{Cl}$

6) $-\mathrm{CN}$

7) $-\mathrm{NO}_{2}$ b)

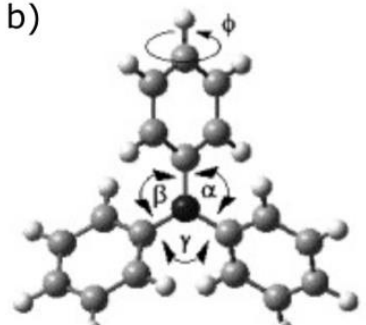

Molecular structure of TPA

c)

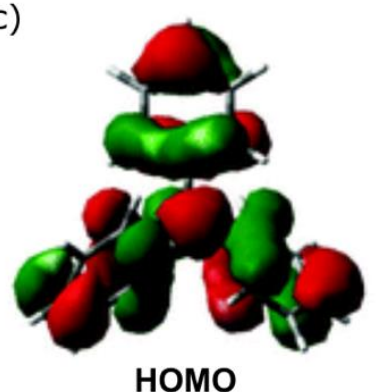

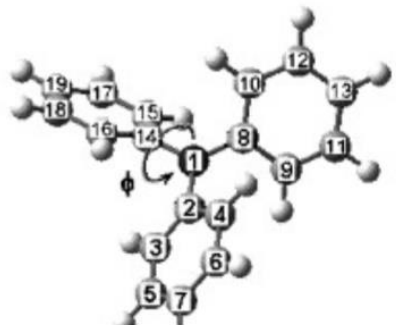

Top view of TPA

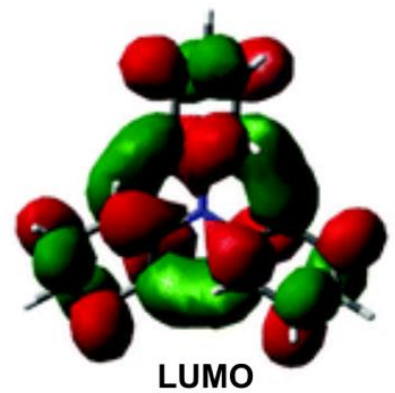

Figure 1: a) Chemical structures of TPA and para-substituted derivatives. b) Propeller like structure of TPA with three tilted phenyl rings. Adapted from ref. 25. c) DFT calculated HOMO and LUMO for TPA. Figure adapted from ref. 4.

Figure 1c shows DFT calculations of the frontier molecular orbitals of TPA. The HOMO of TPA is delocalized over the whole molecule, with highest amplitude of the energy density over the phenyl rings and the p-orbital of the central nitrogen. In the case of the LUMO no contribution of the central nitrogen is observed.

The molecule oxidation and therefore removal of an electron from the HOMO causes a limited change of the electron density on the nitrogen, and ortho, meta, para position on phenyl rings. ${ }^{23}$

According to Gescheidt et al. the calculated ionization potential $\left(I_{p}\right)$ of TPA is 6.608 $\mathrm{eV}$; it is index of the good electron-donating capability of the molecule. ${ }^{4}$ Calculated $\mathrm{HOMO}$ and LUMO levels for TPA are $-5.188 \mathrm{eV}$ and $-0.720 \mathrm{eV}$, respectively. ${ }^{4}$ The effects of substituents (Figure 1a) on HOMO-LUMO levels, ionization potentials and on the molecular geometry of TPA have been widely investigated through the years. ${ }^{4,26-28}$ 
Electron-donating groups such as amino or alkoxy substituents in para position of TPA induce an increase of the $\mathrm{HOMO}$ and a decrease of $I_{p}$. Electron-withdrawing groups such as nitro or halide substituents in para position mainly change the LUMO position. ${ }^{4,5,12}$ Table 1 gives the representative calculated values for differently para-substituted triphenylamine derivatives. Pan et al. found a correlation between Hammett parameters, calculated ionization potentials and HOMO levels for several mono and multi-substituted molecules. ${ }^{29}$

\section{Table 1}

The electrochemistry of this class of molecules has been extensively studied through the years. ${ }^{30-35}$ The one-electron oxidation of TPA generates a radical cation which is unstable as a consequence of the high spin density at the para position and undergoes dimerization to $N, N, N^{\prime}, N^{\prime}$-tetraphenylbenzidine (TPB). This EC mechanism for the electrochemically induced dimerization of TPA to TPB is shown in Scheme 1. It involves a chemically irreversible coupling of two radical cations $\left(\mathrm{TPA}^{-+}\right)$to generate a doubly charged tetraphenylbenzidine moiety $\left(\mathrm{TPB}^{2+}\right)$. The process is followed by elimination of two protons and rearomatization to a neutral TPB. The dimer is more easily oxidized than the corresponding monomer. In the potential range of TPA radical cation formation, TPA is therefore instantaneously oxidized to the dication over its radical cation. 


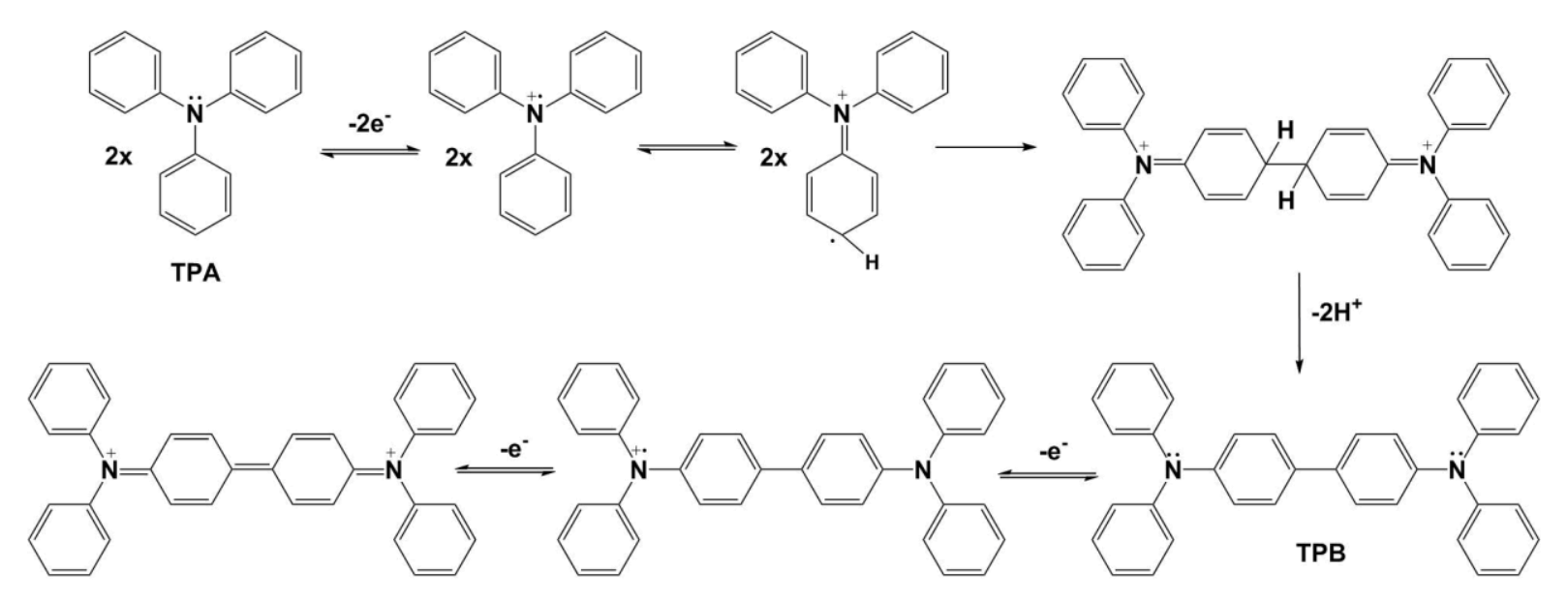

Scheme 1: Mechanism towards TPB formation upon electrochemical oxidation of TPA.

Figure 2 shows the two first voltammetric cycles measured of a TPA solution 34 ; the different peak patterns obtained for the two cycles are evidence of the dimerization of TPA to TPB. In the first oxidation scan only one high peak at $0.69 \mathrm{~V} v s \mathrm{Fc} / \mathrm{Fc}^{+}$is observable. This peak can be associated to the chemically irreversible oxidation of TPA to its radical cation, which undergoes in the time scale of the experiment a follow up reaction to TPB. In the same potential range for which the radical cation of TPA is formed, the more conjugated dimer is immediately oxidized to its dicationic state. In the reverse voltammetric sweep the so formed TPB dication is reduced through two reversible steps, first to the radical cation $(0.41 \mathrm{~V})$ and then, for less positive potential values, to the neutral dimer $(0.16 \mathrm{~V})$. The reversible redox switching of the dimer is fully observable in the second voltammetric cycle. Evidence of the dimerization process is supported by spectroelectrochemical measurements (Figure 2). ${ }^{34}$ At the beginning of the first oxidation scan, the formation of TPA radical cation, $\mathrm{TPA}^{+}$, is associated with the appearance of absorption bands with maxima at $340 \mathrm{~nm}, 562 \mathrm{~nm}$ and $658 \mathrm{~nm}$ (see spectra at $0.52 \mathrm{~V}$, Figure $2 b)$. The increase of the oxidation potential at more positive values, which results 
in a distinctive oxidation peak at $0.69 \mathrm{~V}$, is associated with the formation of new bands with maxima of absorption at $484 \mathrm{~nm}$ and $722 \mathrm{~nm}$, respectively. These bands are associated to the oxidized forms of the dimer, i.e. the radical cation TPB ${ }^{+}$and the dication $\mathrm{TPB}^{2+}$ (see spectra at $0.61-0.69 \mathrm{~V}$, Figure $2 \mathrm{~b}$ ). A further increase of the oxidation potential leads to the disappearance of $\mathrm{TPA}^{++}$and $\mathrm{TPB}^{++}$bands with simultaneous increase of $\mathrm{TPB}^{2+}$ absorption (see spectra at $0.79-1.09 \mathrm{~V}$, Figure $2 \mathrm{~b}$ ). The development of the absorption spectra in the backward scan, as the polarization potential is decreased to the initial value, shows the vanishing of $\mathrm{TPB}^{2+}$ absorption in favor of TPB ${ }^{+}$and neutral dimer TPB. The absence of absorption for TPA indicates the complete reaction of its radical cations upon oxidation (Figure 2c). Electrochemical and absorption data for TPA and TPB and associated redox species upon electrochemical oxidation in solution are resumed in Table 2.

The HOMO level of TPA and TPB extrapolated from $E_{o x, I}^{p}$ (TPA) and $E_{o x, I}^{1 / 2}$ (TPB) values of $\mathrm{CV}$ measurements are -5.79 and $-5.35 \mathrm{eV}$ (taking $5.1 \mathrm{eV}$ for $\mathrm{Fc} / \mathrm{Fc}^{+}$to relate the electrochemical scale to the energy scale), respectively, well correlating with literature values. $^{36}$ 

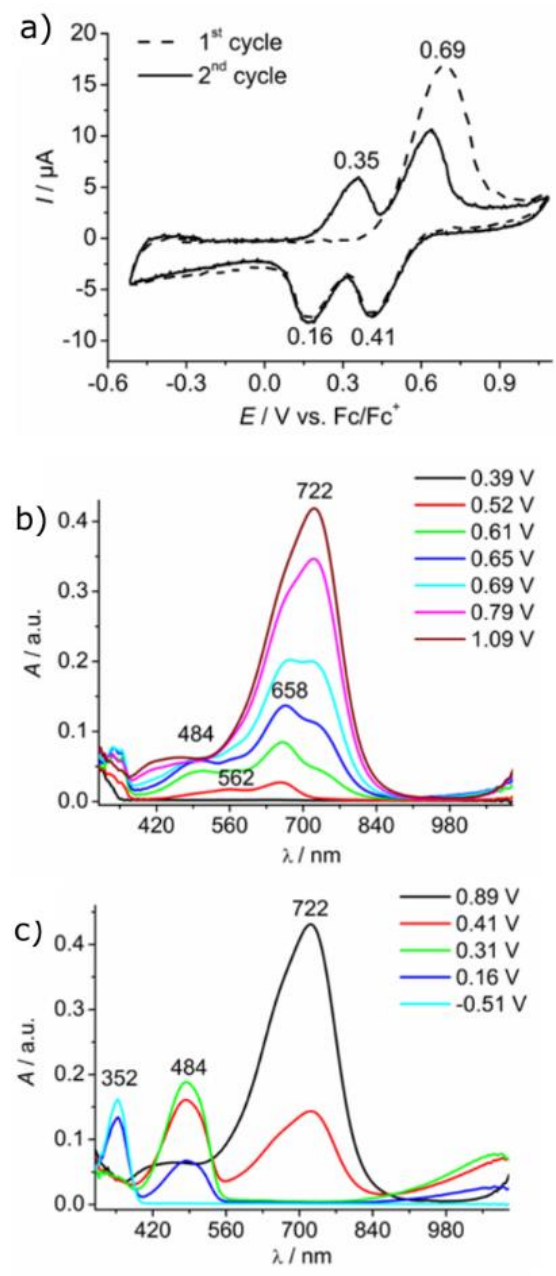

Figure 2: TPA oxidation in thin layer cell $\left(0.1 \mathrm{M}\right.$ TBAPF $/ \mathrm{CH}_{2} \mathrm{Cl}_{2}$; scan rate $\left.20 \mathrm{mV} / \mathrm{s}\right)$, in situ spectroelectrochemical measurements. a) CV measurement with in situ UV-vis absorption spectra recorded for the first voltammetric cycle during b) charging and c) discharging. Figures adapted from ref. 34.

\section{Table 2}

As previously stressed, TPA dimerization takes place through an oxidative coupling mechanism, a similar mechanism is found in the initial steps of electrochemical polymerization of conjugated monomers, leading to similar considerations relating to the process. ${ }^{37}$ By analogy with $\pi$-conjugated monomers, ${ }^{37-39}$ the electronic and steric effects of substituents in TPA para positions can dramatically influence the reactivity of radical 
cation towards the coupling reaction. ${ }^{30,40}$ Radical cations can be stabilized by increasing the conjugation length of the system or introducing electron donor groups such as alkyl, alkoxy or amino groups in appropriate positions. ${ }^{39}$ Furthermore, the presence of sterically hindered substituents and the blocking of reactive sites (end-capping) is a successful strategy for preventing the coupling process. ${ }^{41,42}$

In this context, we compared the coupling behaviour of a set of TPA molecules, namely unsubstituted TPA and tri- $p$-tolylamine $\left(p\right.$-TTA). ${ }^{34}$ Contrary to TPA, the oneelectron oxidation of $p$-TTA leads to the formation of stable radical cation species. This was evidenced by constant intensity EPR spectra for the in-situ generated radical cation species, ${ }^{30}$ by a reversible oxidation pattern in CV measurements and by the presence of characteristic radical cation bands observed during in-situ spectroelectrochemical measurements. We could show how the oxidation of the tri-substituted TPA at the dication level leads to different chemical follow-up reactions, through two competing reaction pathways (Figure 3). The first pathway involves an irreversible intramolecular coupling reaction leading to the formation of a carbazole unit; as also reported by Nelson and coworkers. ${ }^{43}$ The second pathway is constituted by a reversible intermolecular coupling leading to different sets of $\sigma$ dimers, depending on the coupling position. These species were observed to be stable in the charged state and discharge only at relatively negative potentials. The relative amount of these follow-up products is temperature dependent. In particular, the intermolecular coupling appears to be favoured at lower temperatures due to the higher value of the dielectric constant and entropic effects. ${ }^{34}$ 


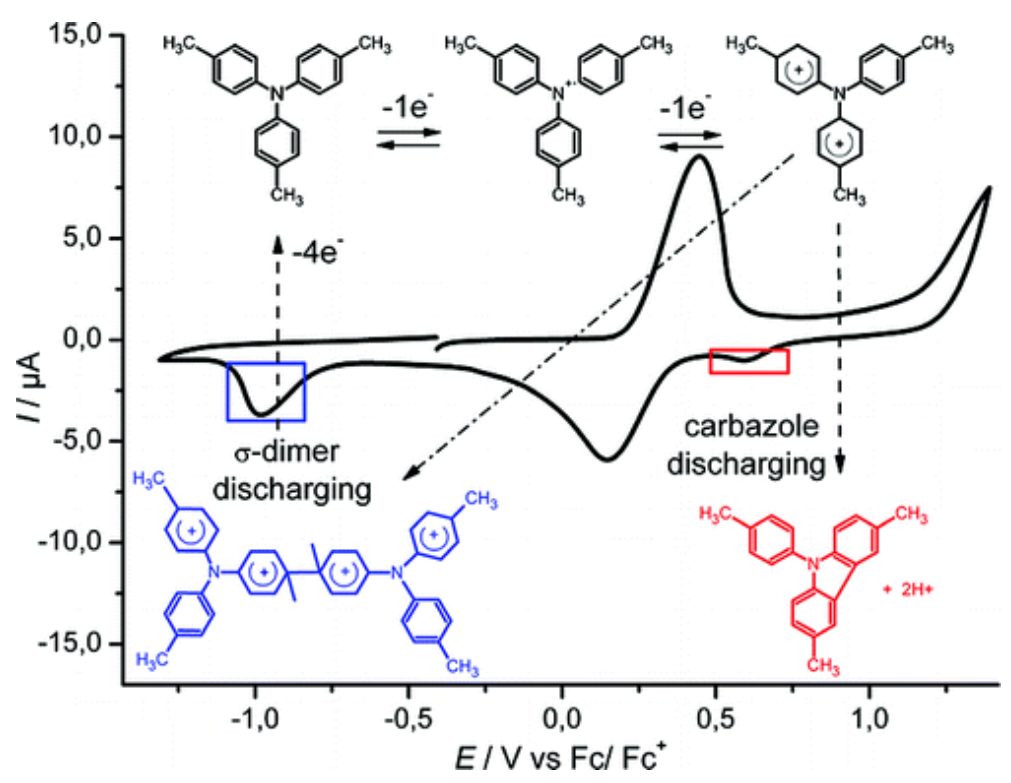

Figure 3: $\mathrm{CV}$ in thin layer cell of tri- $p$-tolylamine in TBAPF $6 / \mathrm{CH}_{2} \mathrm{Cl}_{2} 0.1 \mathrm{M}$, scan rate $20 \mathrm{mV} / \mathrm{s}$, with peak assignment for the products of the reversible and irreversible follow up reactions from ref. 34.

\section{Crosslinking in polymer films for stable redox-active films}

The dimerization ability of TPA units at the level of radical cations has been also observed in polymer systems bearing electroactive TPA units as side groups. ${ }^{34,44-46}$ In this case TPA acts as an electrochemical crosslinker upon oxidation, generating polymers modified with redox-active tetraphenylbenzidine units. In the literature one can find several examples of electrochemical crosslinking of polymers bearing covalently bound redox active pendants capable of oxidative coupling. ${ }^{47,48}$ This approach constitutes an attractive pathway for the preparation of conductive films, as alternative to the more commonly employed deposition of chemically synthesised polymers and the electrochemical polymerizations of $\pi$-conjugated monomers. The said strategy includes in a first step the deposition of chemically synthesised polymers through solution casting methods and, in 
a second step, the oxidative crosslinking/dimerization of the redox active units initiated either chemically or electrochemically resulting in crosslinked films.

We herein discuss two examples of our group on the application of TPA as redoxactive crosslinking units as pendants of a polystyrene and a polythiophene backbone. Particular focus is put on the elucidation of the conductivity behavior of these redox and conjugated redox polymers respectively.

a)
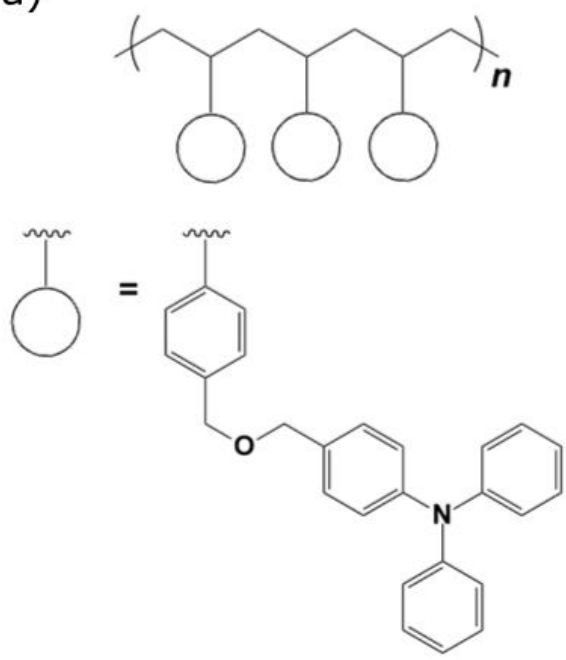

b)

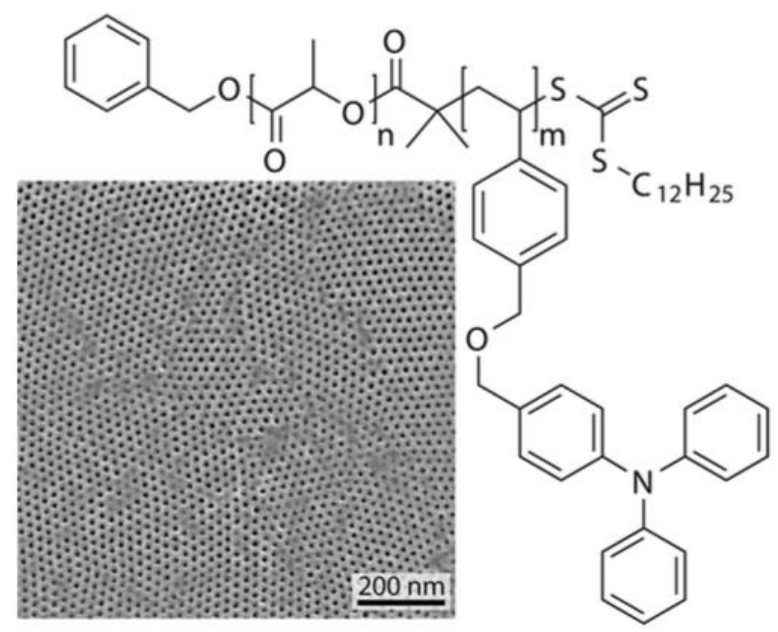

Figure 4: Chemical structures of a) PSTPA (ref. 44) and b) Chemical structure of PSTPA- $b$-PLA diblock copolymer, consisting of a triphenylamine side group polymer block and a poly(D,L-lactide) block (PLA); SEM image of the surface of an electroactive PSTPA porous template structure after PLA removal. Figure adapted from ref.36.

The polymer PSTPA (Figure 4a) is composed of a polystyrene backbone bearing TPA electroactive units attached via dimethyl ether spacers. ${ }^{44}$ Thin films of this redox polymer were deposited on electrodes (ITO or interdigitated electrodes) and the coupling and conductivity mechanism upon electrochemical oxidation was investigated by means of in situ spectroelectrochemistry and CV coupled with conductance measurements. The CV pattern of these films is identical to TPA molecular systems, which means dimerization 
into TPB systems in the first cycle and reversible redox chemistry of TPB in the second and following cycles, Figure 5a. The CV suggests full crosslinking, no free pending TPA moieties seem to remain in these films. The conductance profile in the second cycle (Figure 5b) is endowed with two independent, partially superimposing conductivity regimes associated to two discrete mixed valence states for radical cation and dication, respectively. ${ }^{37,44}$ The conductivity behavior observed for this system at both radical cation and dication level can be described in analogy to the conductivity mechanism in radical ion salts ${ }^{49}$ and redox polymers. ${ }^{50}$ These systems are nonconductive both in the neutral and fully oxidized state and the charge transport is ascribed to the one electron interchain hopping process between oxidized and reduced sites of a redox state, with maximum conductivity reached for an equal number of oxidized and reduced sites. The sketch in Figure $5 b$ highlights the conductivity regimes of inter and intra molecularly linked TPB units. In analogy to this behavior, Heinze et al. observed a conductivity pattern for a 3D hybrid network with sexithiophene oligomers bridging dendrimeric cores, with maximum conductivity reached for half charge level. ${ }^{51}$ 
a)
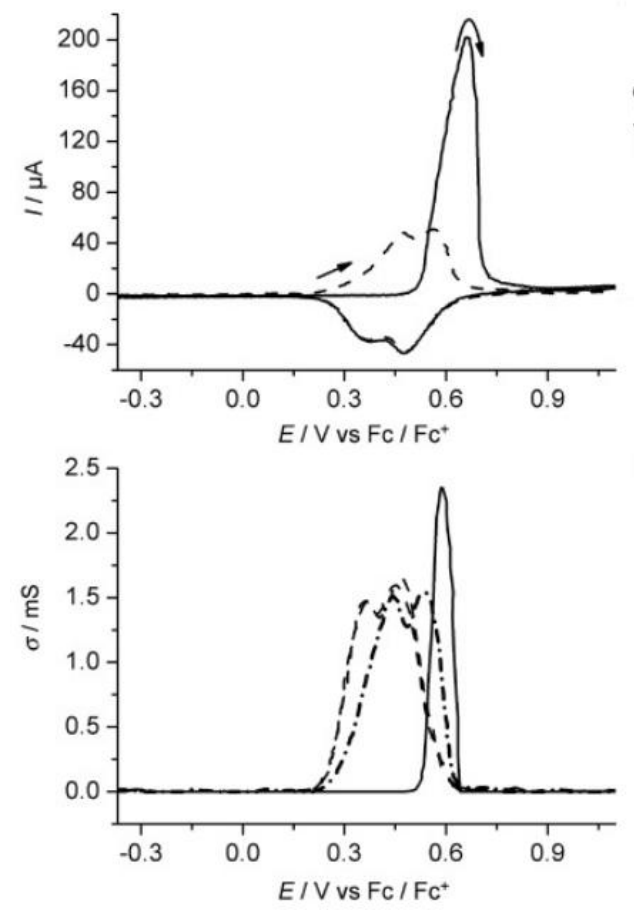

b)
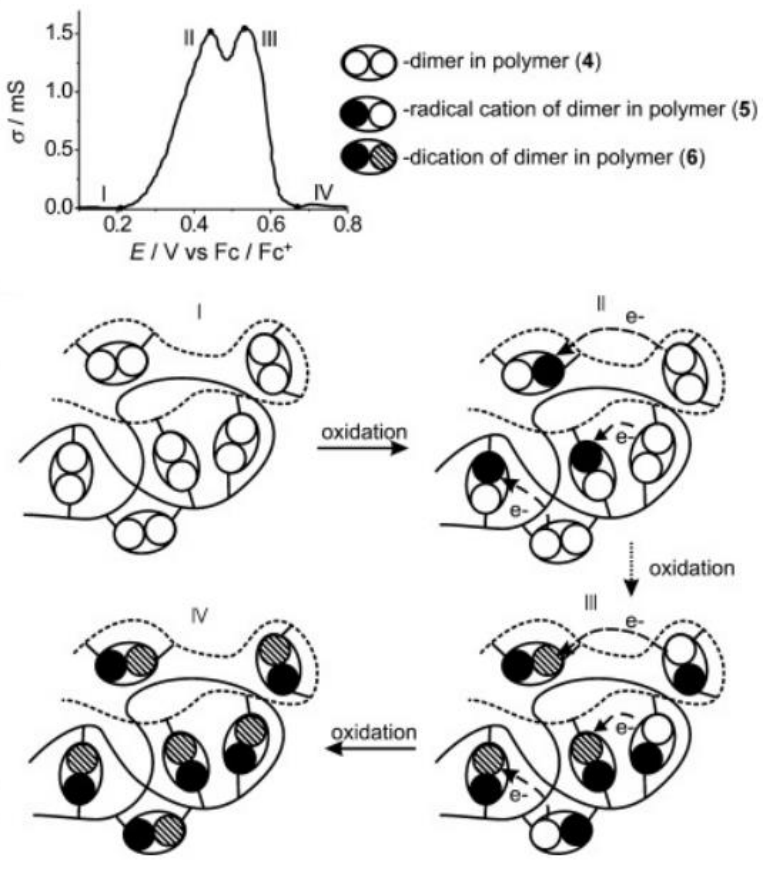

oxidation

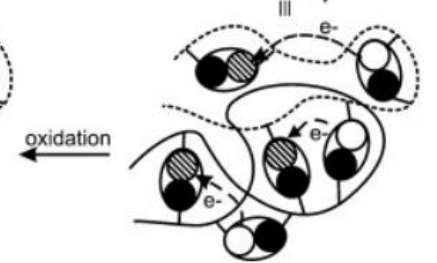

Figure 5: a) CV and in situ conductance measurements for PSTPA polymer films (MeCN/TBAPF 6 $0.1 \mathrm{M}$; scan rate $20 \mathrm{mV} / \mathrm{s}$ ), first and second cycle and corresponding in situ conductance pattern measured simultaneously. b) Explanation of the respective redox species and conductivity profile in crosslinked PSTPA polymer films. Figures adapted from ref. 44.

The redox polymer PSTPA was further integrated as block into a block copolymer giving an interesting example of a microphase-separated architecture proving the versatility of this class of material. ${ }^{36}$ With reference to earlier studies where a polystyreneblock-polylactide block copolymer allowed preparation of nanoporous templates for applications in perovskite solar cells, ${ }^{52,53}$ PSTPA was connected to poly(lactide) (PLA). These PSTPA-block-PLA block copolymers have a cylindrical bulk morphology, with PSTPA constituting the majority component. Polymer films characterized by perpendicularly oriented cylinders at the surface and a tortuous inner structure are spontaneously formed directly after spin casting (Figure 4b). The cylinders have a center- 
to-center distance of $21 \pm 2 \mathrm{~nm}$ and an average diameter of $13 \pm 2 \mathrm{~nm}$. The employment of PLA block allows its degradation through mild hydrolysis conditions, ${ }^{54,55}$ leading to a nanoporous structure in the PSTPA semiconducting matrix. After etching, the obtained porosities can be further functionalized through the filling of the whole pore structure with diverse types of materials, also exploiting TPA electroactivity and crosslinking into TPB. ${ }^{56}$

The second polymer, namely PT-TPA, constitutes of a linear regioregular polythiophene backbone bearing TPA redox pendants connected to the main backbone via click chemistry ${ }^{57}$ (Figure 6). Films can be prepared by classical solution deposition, e.g. spin-coating. The dimerization ability of the pendant TPA was exploited for post deposition crosslinking and its effects on film absorption, redox and conductivity characteristics were analyzed. In PT-TPA thin films, the oxidation potential of TPA/TPB redox units and of the polythiophene backbone falls in the same region, resulting in the simultaneous generation of charge carriers. One can talk about redox-matching in this context. CV measurements and in situ spectroelectrochemistry on solution-cast PT-TPA films give evidence of the successful dimerization of TPA to TPB into crosslinked films. Figure 6a shows the CV of such a crosslinked PT-TPA film. The corresponding conductance profile reveals a plateau-like pattern which is similar to the one found in literature for many conjugated polymers ${ }^{37}$ and confirms the supremacy of the thiophene conjugated backbone in determining the conductivity characteristics, (see Figure 6a). However, in situ spectroscopy also clearly shows the oxidized species of TPB which means they do contribute to the overall conductivity. Based on these findings a classification into conjugated redox polymers is well suitable.

Motivated by successful electrochemical doping, we also explored chemical doping strategies. We could show how post deposition modification of PT-TPA films involving 
TPA oxidative coupling (i.e. crosslinking) can be successfully performed through the employment of chemical oxidants. In literature the polymerization and doping of polythiophenes as well as triphenylamine and carbazole polymerization could be induced by $\mathrm{FeCl}_{3} .{ }^{58,59}$ When using $\mathrm{FeCl}_{3}$ as oxidizing agent for PT-TPA, the effectiveness of crosslinking was evidenced by the appearance of bands associated to TPB and its doped forms TPB ${ }^{+}\left(\lambda_{\max } \sim 465 \mathrm{~nm}\right)$ and TPB $^{2+}\left(\lambda_{\max } \sim 757 \mathrm{~nm}\right)$ together with the ones of polythiophene backbone charging with $\mathrm{PT}^{\cdot+}\left(\lambda_{\max } \sim 837 \mathrm{~nm}\right)$ and $\mathrm{PT}^{2+}\left(\lambda_{\max } \sim 1050 \mathrm{~nm}\right)$ species. This is in analogy to what was detected during in situ spectroelectrochemical measurements. The use of such an oxidizing agent leads therefore to the simultaneous crosslinking and doping of the polymer film, similarly to the electrochemical process. The variations brought by chemically induced oxidative crosslinking and doping on PT-TPA conductivity were also analyzed by means of four-point probe measurements, revealing high conductivity values of $8 \pm 2.1 \mathrm{~S} \cdot \mathrm{cm}^{-1}$ for PT-TPA doped via $\mathrm{FeCl}_{3}$ (Figure $6 \mathrm{~b}$ ).

Crosslinking was also associated to a significant decrease of solubility, making the polymer films insoluble in different organic solvents, from which non-crosslinked films could be solubilized. Post-deposition crosslinking becomes therefore an interesting approach for applications employing organic solvents, and for which dissolution of the active material is a limiting factor. We envision that the simultaneous crosslinking and doping might be a new concept for the preparation of hole-transport layers in OPV or OLEDs as well as organic thermoelectric devices. 
a)
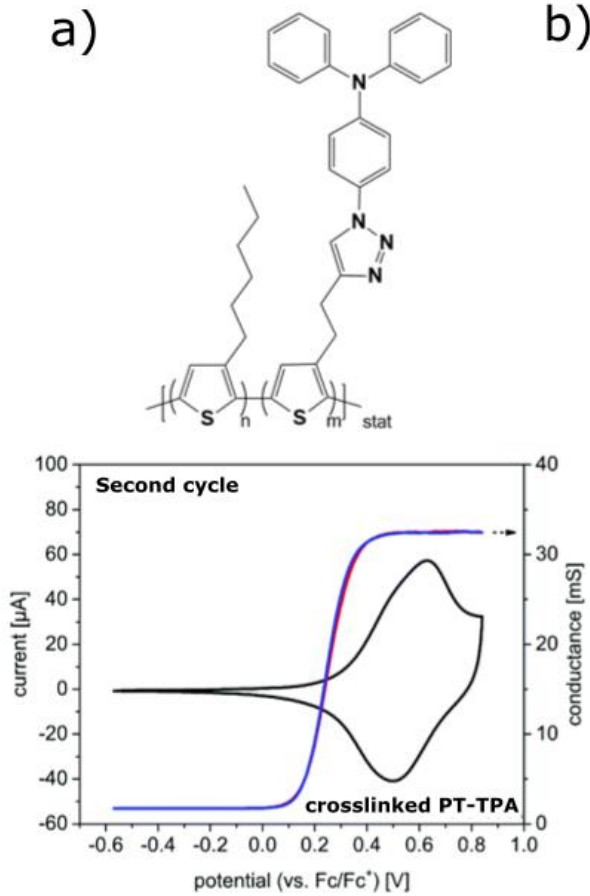

b)
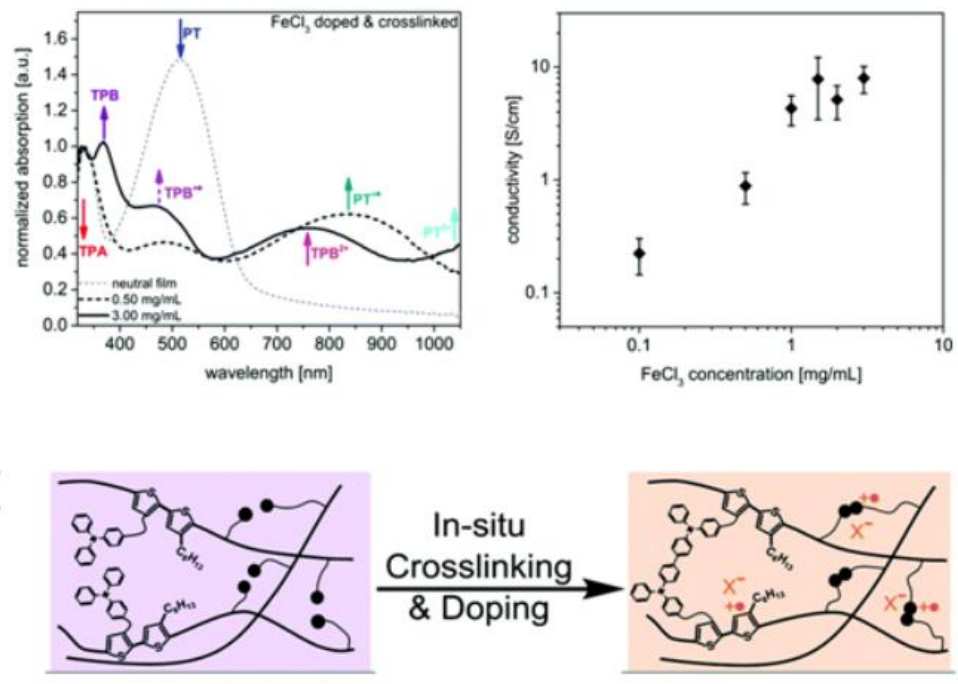

Figure 6: a) CV and in situ conductance measurement for a crosslinked PT-TPA thin film b) Absorption spectra and conductivity measurements of crosslinked PT-TPA for different dopant solution $\left(\mathrm{FeCl}_{3} / \mathrm{CHCl}_{3}\right)$ concentrations. Figures adapted from ref. 57 .

\section{Triphenylamine-based push-pull molecular donors for organic photovoltaics}

$D-\pi$-A push-pull molecules based on TPA or aryl derivatives as electron-donating blocks (D) connected via a $\pi$-spacer to various electron-withdrawing blocks $(A)$, have been widely developed as electron-donor materials for OPV. Their combination with electronacceptor materials such as fullerene derivatives via solution or vacuum processing allows the elaboration of efficient planar heterojunction $(\mathrm{PHJ})$ or bulk-heterojunction $(\mathrm{BHJ})$ organic solar cells (OSCs). ${ }^{10-12}$ These push-pull donors can be divided in three main classes depending on their structure, namely star-shaped $D A_{3}, D A D$ and linear $D A$ molecules. 
Star-Shaped $D A_{3}$ push-pull molecules

The development of star-shaped TPA-based push-pull molecules as donor materials in OSCs was pioneered by Roncali and co-workers. ${ }^{60-63}$ One of the first examples, namely $\mathbf{D A}_{\mathbf{3}} \mathbf{- 1}$, was reported in 2006 (Figure 7). ${ }^{60,61}$ This $\mathrm{DA}_{3}$ compound exhibits a central TPA functionalized with three thienyl (T)-dicyanovinyl (DCV) branches at each para position of the benzene rings. The propeller shape of TPA imparts a 3D character to $\mathbf{D A}_{3}-\mathbf{1}$ which is expected to produce amorphous materials with isotropic electronic properties. Bilayer OSCs associating $\mathbf{D A}_{3}-\mathbf{1}$ with $\mathrm{C}_{60}$ as electron-acceptor (ITO/PEDOT-PSS/DA 3 -1/C60/LiF/Al), led to a power conversion efficiency (PCE) of 1.85 $\%$ (at $80 \mathrm{~mW}$ under AM 1.5 simulated solar irradiation). Few years later, the introduction of a hybrid anode buffer layer $\mathrm{MoO}_{3} / \mathrm{Cul}$ led to a PCE of $2.50 \% .{ }^{64}$

The introduction of the electron-withdrawing DCV units in $\mathbf{D A}_{3}-\mathbf{1}$ creates an efficient intramolecular charge transfer (ICT) between the electron-donating $D$ and electronaccepting $A$ units leading to a broad absorption band in the visible spectrum ( $\lambda_{\max }=509$ nm) (Figure 7). In addition, the DCV units induce an increase of the oxidation peak potential of $\mathbf{D A}_{3}-\mathbf{1}\left(E_{\mathrm{pa}^{1}}{ }^{1}=0.64 \mathrm{~V} v s \mathrm{Fc} / \mathrm{Fc}^{+}\right)$corresponding to a deeper $\mathrm{HOMO}$ level which in turn i) produces an exceptionally high open-circuit voltage $\left(V_{o c}=1.15 \mathrm{~V}\right)$ for the bilayer OSC, and ii) provides also a better stability of molecule $\mathbf{D A}_{3}-\mathbf{1}$ towards oxygen. The cyclic voltammogram (CV) of $\mathbf{D A}_{\mathbf{3}} \mathbf{- 1}$ shows a reversible oxidation wave in agreement with a stable radical-cation species. Compared to the high reactivity of the radical cation of TPA, as described above, the insertion of terminal groups at the para position of each phenyl ring combined with the $\pi$-extension of the arms favour the stabilization of the radical cation 
species hence preventing any follow-up dimerization of electropolymerization reactions. Note that compound $\mathrm{DA}_{3}-1$ displays also an irreversible reduction peak at $E_{\mathrm{pr}}{ }^{1}=-1.65 \mathrm{~V}$.
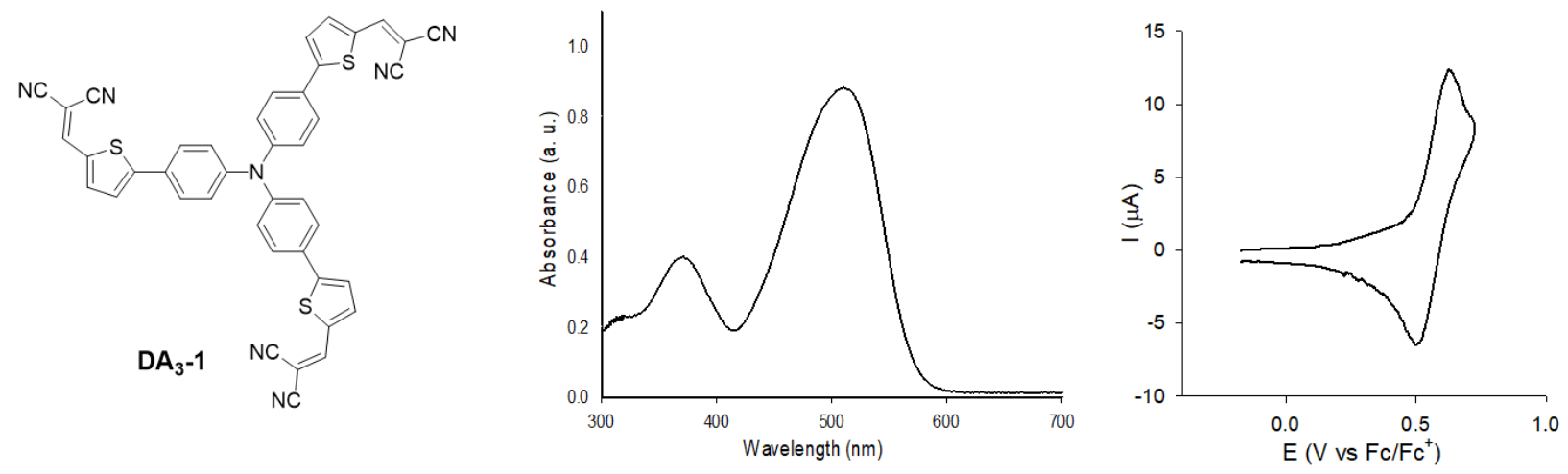

Figure 7: Structure of DA3-1 (left), UV-vis spectrum in $\mathrm{CH}_{2} \mathrm{Cl}_{2}$ (middle) and $\mathrm{CV}$ in $0.1 \mathrm{M}$ $\mathrm{Bu} 4 \mathrm{NPF}_{6} / \mathrm{CH}_{2} \mathrm{Cl}_{2}$ (right), Pt counter and working electrodes, scan rate $100 \mathrm{mV} / \mathrm{s}$. Adapted from ref 60.

Since then, many other $\mathrm{DA}_{3}$ push-pull molecules derived from TPA have been successfully used as donor materials in $\mathrm{BHJ}$ OSCs in the presence of $\mathrm{PC}_{71} \mathrm{BM}$ as acceptor material. ${ }^{11,12}$ Scheme 2 shows representative examples. Brabec, Ponomarenko and coworkers synthesized a series of star-shaped molecules similar to $\mathbf{D A}_{\mathbf{3}}-\mathbf{1}$ with alkylsubstituted DCV end groups and different oligothiophene $\pi$-spacers. ${ }^{65,66}$ For instance, BHJ OSCs fabricated from $\mathrm{DA}_{3}-2$ gave a high PCE of $4.72 \%$ due to the favourable film morphology of the blend with $\mathrm{PC}_{71} \mathrm{BM}$ and to the exceptionally high hole mobility $\left(\mu_{\mathrm{h}}=\right.$ $3.99 \times 10^{-3} \mathrm{~cm}^{2} \mathrm{~V}^{-1} \mathrm{~s}^{-1}$ ) measured on thin-films of $\mathbf{D A}_{3}-2$ by the space charge limited current (SCLC) method. ${ }^{65} \mathrm{Li}$ et al. introduced an electron-deficient benzothiadiazole unit inside each oligothiophene arms leading to $\mathrm{DA}_{3}-3$ that gave a BHJ OSC with PCE of 4.3 $\% .{ }^{67}$ By introducing a fluorine atom on the benzothiadiazole unit to increase its electron affinity and insertion of an electron-rich dithienosilole block to extend the conjugation length of each arm, Ko et.al. reported the synthesis of $\mathbf{D A}_{3}-\mathbf{4}$ and further improved the 
PCE up to $4.7 \% .{ }^{68}$ More recently the diketopyrrolopyrrole (dpp)-based star-shaped molecule DA3-5 was described showing that the nature of the alkyl chains of the dpp has a strong impact on the supramolecular self-assembly. When a branched 2-ethylhexyl chain was used, thin-films showed crystalline domains whereas dodecyl chains in $\mathbf{D A}_{\mathbf{3}} \mathbf{- 5}$ promoted the formation of one-dimensional nanowires beneficial for the PV performance of BHJ OSCs, PCE increasing respectively from $2.9 \%$ to $4.4 \% .69$
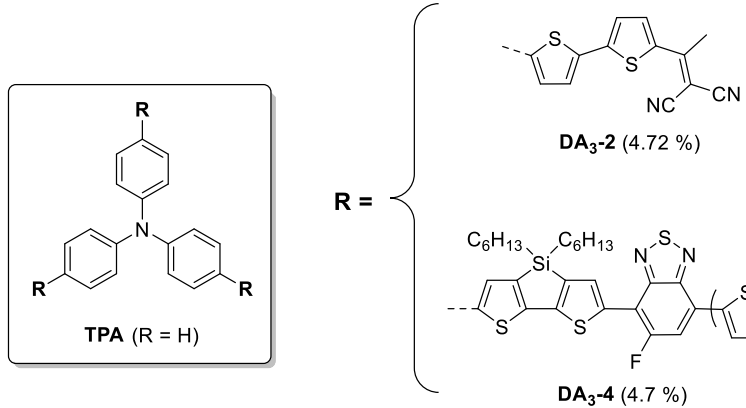

$\mathrm{DA}_{3}-2(4.72 \%)$

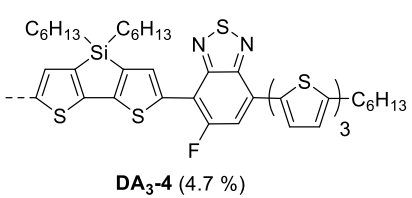

$\mathrm{DA}_{3}-4(4.7 \%)$

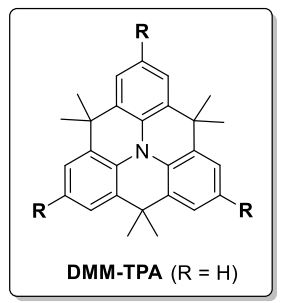

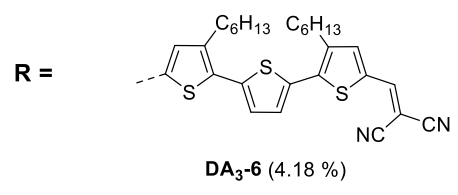

$\mathrm{DA}_{3}-6(4.18 \%)$

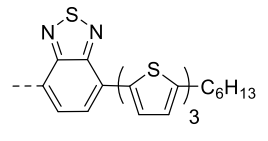

$\mathrm{DA}_{3}-3(4.3 \%)$

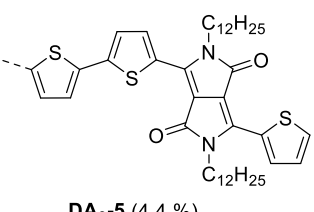

$\mathrm{DA}_{3}-5(4.4 \%)$

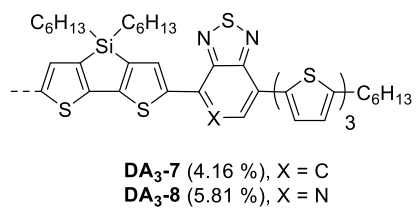

Scheme 2: Representative examples of TPA-based $\mathrm{DA}_{3}$ push-pull donors and PCE values of $\mathrm{PC}_{71} \mathrm{BM}$-based $\mathrm{BHJ}$ single junction OSCs.

Star-shaped push-pull molecules with a central dimethylmethylene TPA-bridged core (DMM-TPA) as active material for OPV have been described by the group of Ko. ${ }^{68,70-}$ ${ }^{72}$ X-ray diffraction data on a single crystal of DMM-TPA show that the dihedral angles between phenyl rings and the plane of the three $\mathrm{N}$-bonded carbon atoms are much smaller in DMM-TPA (ca. $5.9^{\circ}$ and $7.6^{\circ}$ ) than those of TPA $\left(>43^{\circ}\right) .{ }^{73}$ As determined by square wave voltammetry, ${ }^{74}$ the oxidation potential of DMM-TPA is negatively shifted by $c a 0.2 \mathrm{~V}$ 
compared to that of TPA due to its planarized structure combined with the presence of alkyl substituents in ortho positions of the benzene ring. In addition, the reversibility of the oxidation wave of DMM-TPA shows an enhanced stability for the radical cation, ${ }^{74}$ even making possible the access to radical cation salts. ${ }^{75}$ Thus, DMM-TPA is expected to improve intramolecular $\pi$-electronic delocalization and favour intermolecular interactions resulting in increasing hole mobility and PV performance. BHJ OSCs with $\mathbf{D A}_{\mathbf{3}}-\mathbf{6}$ with three arms based on terthiophene bridge end-capped with a DCV unit, gave a PCE of $4.18 \% .{ }^{71}$ Compound $\mathbf{D A}_{3}-\mathbf{7}$ with arms including a dithienosilole and a benzothiadiazole unit shows in solution an ICT band at $543 \mathrm{~nm}$ which is red-shifted by $2 \mathrm{~nm}$ compared to its TPA analogue whereas this shift increases to $20 \mathrm{~nm}$ for thin-films. ${ }^{70}$ The HOMO level of DA3$7(-5.24 \mathrm{eV})$ slightly increases as compared to that of the TPA counterpart $(-5.29 \mathrm{eV})$. The best BHJ OSCs with $\mathrm{DA}_{3}-7$ gave a PCE of $4.16 \%$, higher than the value obtained in the same conditions for the TPA analogue $(P C E=3.49 \%)$. This improvement was attributed to the efficient intermolecular $\pi-\pi$ packing interactions and to the enhanced hole mobility of $\mathbf{D A}_{3}-7$. Remarkably, the replacement of the benzothiadiazole unit by a thiadiazolopyridine ring in $\mathbf{D A}_{3}-8$ has led to $\mathrm{BHJ}$ OSCs with a maximum PCE of $5.18 \%$ which is again higher than the one obtained for the TPA analogue $(P C E=3.88 \%)$ and represents one of the highest $P C E$ ever reported for a $\mathrm{DA}_{3}$ system. ${ }^{72}$ 


\section{DAD push-pull molecules}

TPA-derived push-pull molecules with a DAD structure have also been investigated for OPV. Their synthesis relies on mono-functionalized TPA which makes the synthesis easier. The choice of the electron-deficient core A can significantly affect the PV performance although the architecture of the devices plays also a crucial role. Several solution-processable $(X=1-5)$ and vacuum-deposited $(X=6,7)$ DAD-X systems leading to OSCs with high PCEs are represented in scheme 3. The dicyanomethylenepyrane (DAD-1), ${ }^{76}$ thieno[3,4-c]pyrrole-4,6-dione $\left(\right.$ DAD-2) ${ }^{77}$ or thiazolothiazole $\left(\right.$ DAD-3) ${ }^{78}$ derivatives were combined with $\mathrm{PC}_{71} \mathrm{BM}$ to prepare $\mathrm{BHJ}$ with $\mathrm{PCE}$ of $2.10 \%, 3.31 \%$ and $4.05 \%$ respectively. This improvement is due to the nature of the electron-deficient unit $A$ and also to the progressive $\pi$-extension of the conjugated bridge between the TPA and A. As developed by Li et al., one approach consists in using a central electron-deficient benzothiadiazole flanked with different $\pi$-extended systems. ${ }^{79}$ Thus a PCE of $4.86 \%$ was obtained with a $\mathrm{BHJ}$ combining $\mathrm{PC}_{61} \mathrm{BM}$ and DAD-4 that exhibits a fluoro-substituted benzothiadiazole ring. ${ }^{80}$

The groups of Wong and Forrest have been particularly interested in vacuumprocessed planar heterojunction OSCs. For example, the small DAD-6 molecule with one rigid fluorenylidene malononitrile core was used for preparing co-evaporated $\mathrm{BHJ}$ with $\mathrm{C}_{60}$ or $\mathrm{C}_{70}$, giving a PCE of $3.12 \%$ and $4.04 \% .{ }^{81}$ On the other hand, Forrest et al. have developed squaraine derivatives such as compound DAD-7 for bilayer OSCs with $\mathrm{C}_{60}$ which upon thermal annealing produce $5.2 \%$ efficiency. ${ }^{82,83} \mathrm{It}$ is worth noting that a further increase of PCE up to $5.7 \%$ has been achieved by replacing the TPA units by a $N, N$ - 
diphenylnaphthalen-1-amine that favours $\pi$-stacking and hence, improved charge transport and exciton diffusion.

Finally, solution-processed BHJ OSCs based on DAD-5 gave a high PCE reaching $6.13 \%$; this benzothiadiazole derivative is indeed a $D_{1} A D_{2} A D_{1}$ system with a central electron-rich dithienobenzene flanked by two alkylated thiophene substituents. ${ }^{84}$
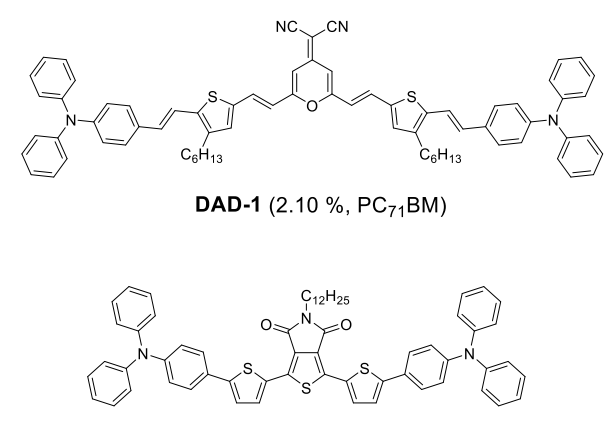

DAD-2 $\left(3.31 \%, \mathrm{PC}_{71} \mathrm{BM}\right)$
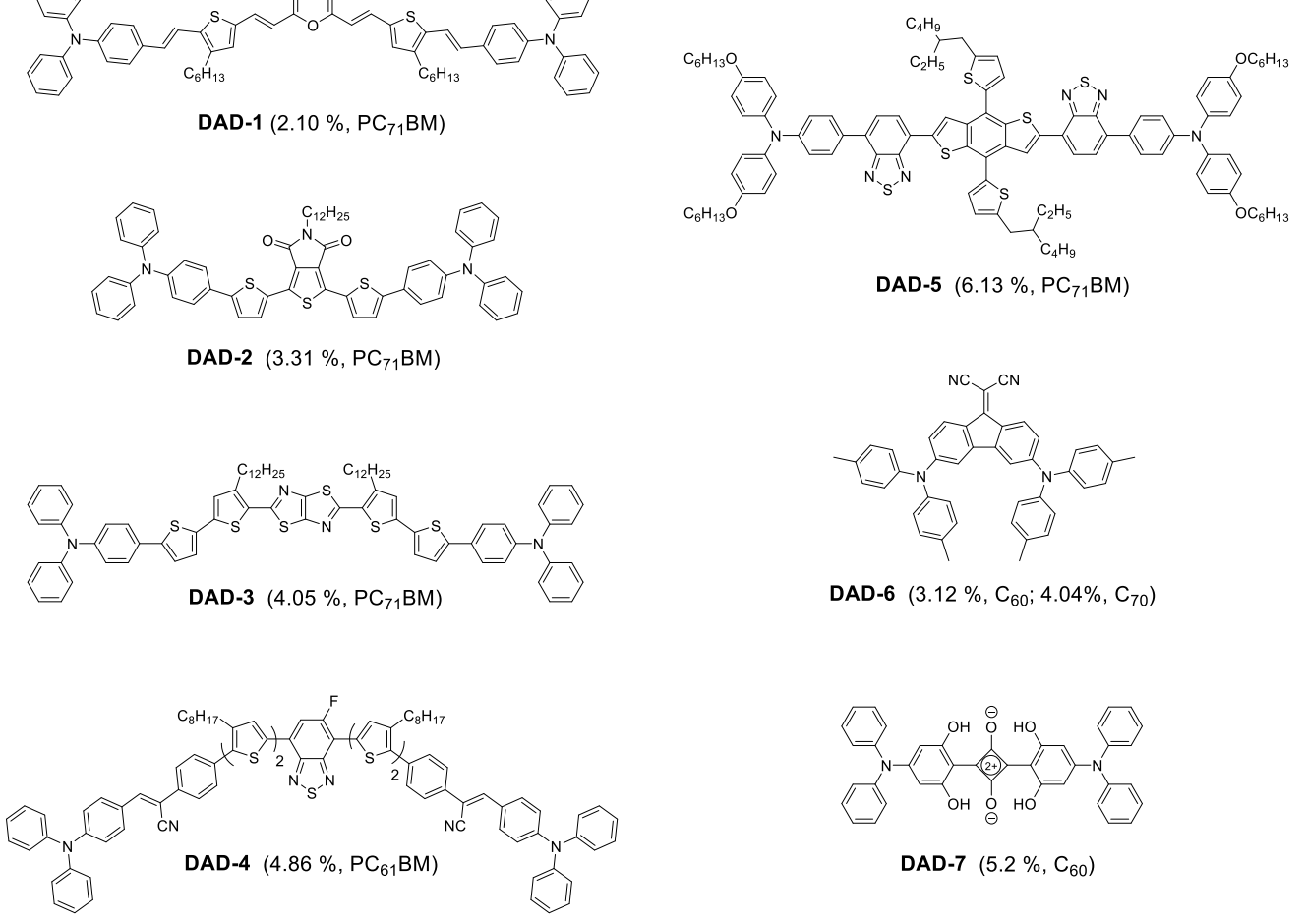

DAD-7 $\left(5.2 \%, \mathrm{C}_{60}\right)$

Scheme 3: Representative examples of TPA-based DAD push-pull donors and related PCE of single junction OSCs.

Our group has developed a series of DAD systems (DAD-8) based on 1,1,4,4tetracyanobuta-1,3-diene (TCBD) as a new electron-accepting group A for OPV (Figure 8). ${ }^{85}$ The latter was used in 2001 by Jen et al. in dipolar $D-\pi$-A chromophores for application in nonlinear optics. ${ }^{86}$ The chemistry of TCBD was further explored by the group of F. Diederich. ${ }^{87}$ The TCBD moiety is easily obtained via a [2+2] cycloaddition between tetracyanoethylene and acetylene derivatives preferably substituted by electron-releasing 
substituents, this "click"-type reaction is highly efficient and, in principle, does not produce by-products.
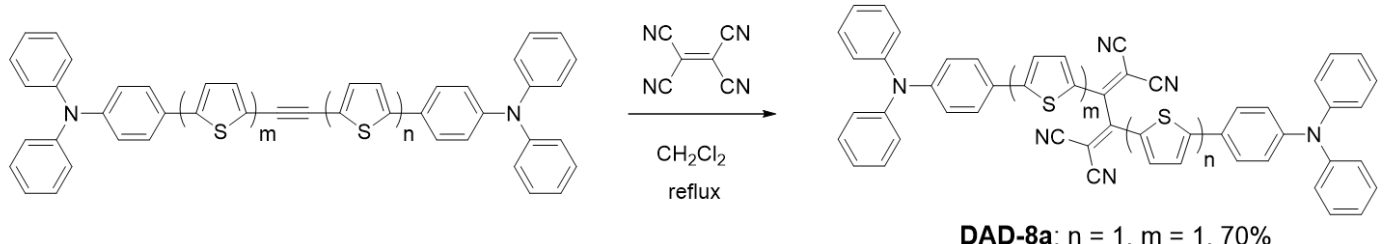

DAD-8a: $n=1, m=1,70 \%$

DAD-8b: $n=1, m=2,68 \%$

DAD-8c: $n=2, m=2,90 \%$
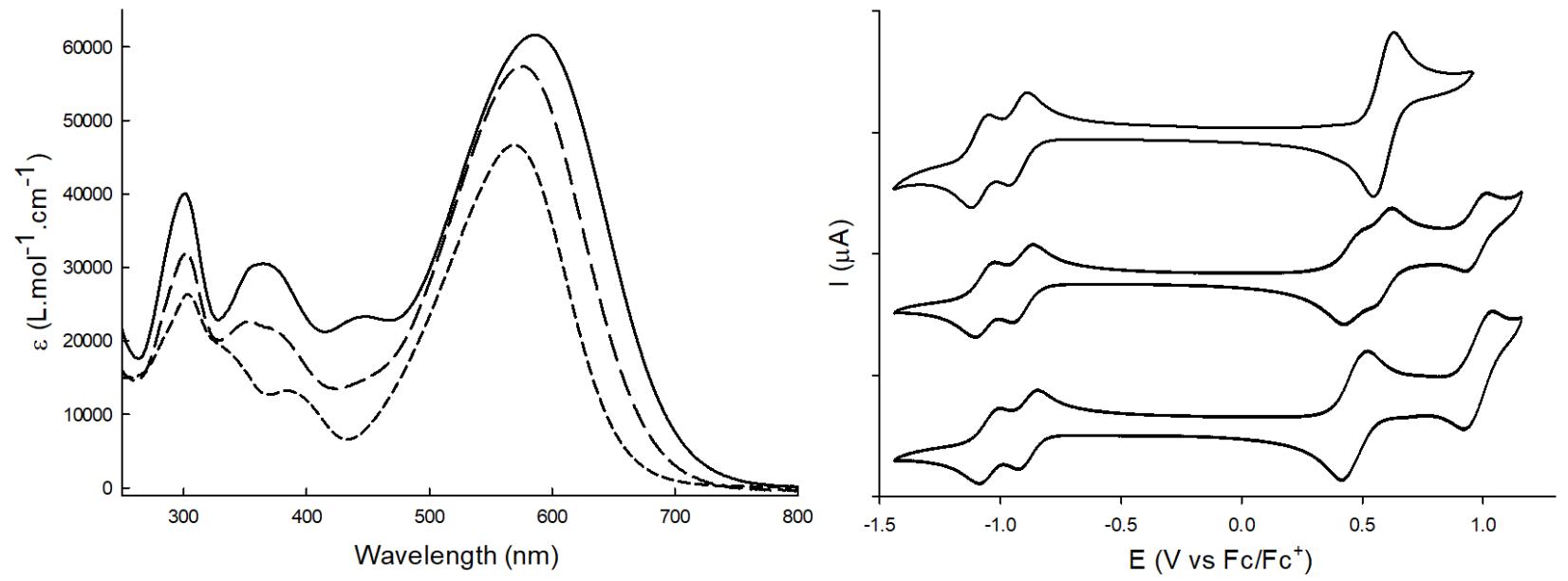

Figure 8: Synthesis of DAD-8. Left: Absorption spectra of DAD-8a (solid line), DAD-8b (long dashed line) and DAD-8c (short dashed line) in $\mathrm{CH}_{2} \mathrm{Cl}_{2}$. Right: CVs of DAD-8a (top), DAD-8b (middle) and DAD-8c (bottom) $0.5 \mathrm{mM}$ in $0.1 \mathrm{M} \mathrm{Bu}_{4} \mathrm{NPF}_{6} / \mathrm{CH}_{2} \mathrm{Cl}_{2}$, Pt working electrode, scan rate $100 \mathrm{mV} / \mathrm{s}$. Adapted from ref. 85.

The UV-vis spectra of compounds DAD-8 show an intense broad ICT band that shifts from $569 \mathrm{~nm}$ for DAD-8a to $576 \mathrm{~nm}$ and $586 \mathrm{~nm}$ for DAD-8b and DAD-8c, respectively, in agreement with the progressive extension of the $\pi$-conjugation (Figure 8, left).

The CV of DAD-8a (Figure 8, right) exhibits a two electron reversible oxidation wave with anodic peak potential $E_{\mathrm{pa}}{ }^{1}$ at $0.63 \mathrm{~V} v s \mathrm{Fc} / \mathrm{Fc}^{+}$assigned to the simultaneous oneelectron oxidation of the two lateral thienyl-TPA branches. The CV of DAD-8a shows also two successive one-electron reduction waves at $E_{\mathrm{pr}}{ }^{1}=-0.97 \mathrm{~V}$ and $E_{\mathrm{pr}}{ }^{2}=-1.13 \mathrm{~V}$ associated to the reduction of the central strong electron-withdrawing TCBD unit; close 
values are observed for DAD-8b and DAD-8c. On the other hand, the lengthening of the oligothiophene chain in DAD-8b and DAD-8c induces a negative shift of $E_{\mathrm{pa}}{ }^{1}$ with the appearance of additional oxidation peaks at more positive potentials. In particular, the CV of the unsymmetrical compound DAD-8b shows three one-electron reversible oxidation waves peaking at $0.51 \mathrm{~V}, 0.62 \mathrm{~V}$ and $1.02 \mathrm{~V}$. The first and the second processes are assigned to the successive oxidation of the bithienyl- and thienyl-TPA branches to the radical cation whereas the third one can be related to the oxidation of the bithienyl-TPA branch to the dication state. These electrochemical results, in agreement with the small red shift of $17 \mathrm{~nm}$ from DAD-8a to DAD-8C, suggest a relatively weak intramolecular electronic interaction between the two lateral conjugated arms through the central TCBD segment. These experimental results agree well with the DFT-optimized geometry of molecules DAD-8 which exhibit significant dihedral angles of $93-96^{\circ}$ between the planes containing the two DCV groups of TCBD (Figure 9).

Bilayer OSCs were fabricated from a solution-processed thin-film of DAD-8a leading to a PCE of $1.08 \%$, a short-circuit current density $\mathrm{Jsc}_{\mathrm{sc}}$ of $3.06 \mathrm{~mA} \mathrm{~cm}^{-2}$, an opencircuit voltage $V_{o c}$ of $0.97 \mathrm{~V}$ and a fill-factor $F F$ of 0.33 for the best device. This high $V_{o c}$ value can be related to the relatively low HOMO energy level of DAD-8a. Enhanced performance $(P C E=1.72 \%)$ was obtained with the extended derivative DAD-8c in the same conditions while the use of $\mathrm{C}_{70}$ led to PCE higher than $2 \%$ for both compounds DAD-8a and DAD-8c.

With the idea of increasing the scalability and limiting the economic cost and the environmental impact of the synthesis of organic materials for potential industrial application in OPV ${ }^{88}$ Leriche and co-workers from our group have developed the straightforward synthesis of DAD-9 based on a central diiminofumaronitrile acceptor 
group (Scheme 4). This compound was prepared in few steps in good yield by double condensation of a TPA-carbaldehyde derivative with 2,3-diaminomaleonitrile under microwave activation with trifluoroacetic acid (TFA) as catalyst. ${ }^{89}$ The photovoltaic potential of DAD-9 was evaluated in bilayer OSCs with $\mathrm{C}_{60}$ leading to a $1.18 \%$ efficiency. Following a similar approach, Frère and co-workers described the Schiff base DAD-10 with a central electron-deficient benzodifurane core and corresponding bilayer OSCs with $\mathrm{C}_{60}$ reaching a maximum $P C E$ of $1.73 \% .{ }^{90}$
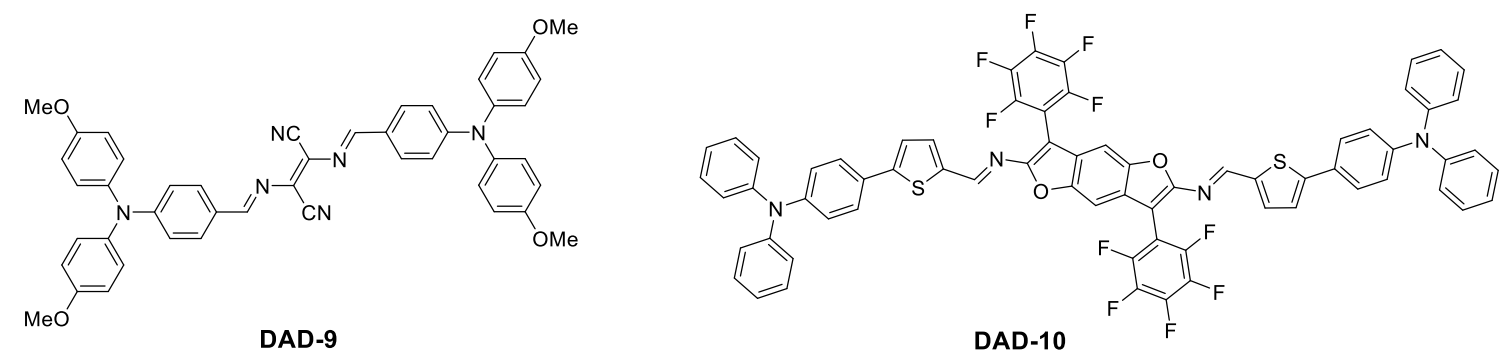

Scheme 4: TPA-based DAD push-pull donors derived from Schiff bases.

\section{Linear DA push-pull molecules}

Compared to previous systems with higher dimensionality, smaller linear DA pushpull molecules have an increased tendency to form aggregates and crystallize which can improve the charge transport properties of related thin-films. They generally present the advantage to be processed in solution or by vacuum deposition leading to homogenous thin-films for the elaboration of bilayer heterojunction or BHJ OSCs.

Scheme 5 shows selected examples of TPA-based DA push-pull molecules for OPV. Compound DA-1 represents one of the first examples reported for OPV. ${ }^{91}$ The $\pi$ spacer between $A$ and $D$ was extended by connecting the nitrogen of TPA to a fluorenyl unit functionalized by a quaterthiophene backbone end-capped with an electron- 
withdrawing DCV unit. A PCE of $2.67 \%$ was obtained for a bilayer OSC with $\mathrm{C}_{60}$. Ko et al. developed DA-2 based on a shorter bithiophene spacer and a modified-TPA with two outermost fluorenyl units, for solution-processed $\mathrm{BHJ}$ with $\mathrm{PC}_{71} \mathrm{BM}$ affording up to $3.66 \%$ efficiency..$^{92}$ The use of a bridged dithienosilole $\pi$-spacer by the group of Wong in DA-3 led to better electronic delocalization resulting in a red shift of the absorption band and a higher extinction coefficient. ${ }^{93} \mathrm{BHJ}$ prepared by co-evaporation of DA-3 and $\mathrm{C}_{70}$ gave a PCE of $3.82 \%$. Extending our initial approach based on the reduced-size DA-10 molecule (see below), Pshenichnikov et al. synthesized DA-4 with an additional phenyl ring on the DCV unit. Compound DA-4 demonstrated extremely long exciton diffusion lengths exceeding $25 \mathrm{~nm}$ in vacuum-deposited films and was co-evaporated with $\mathrm{C}_{70}$ giving $\mathrm{BHJ}$ OSCs yielding a PCE as high as $5.11 \%{ }^{94}$

Again the group of Wong developed a series of push-pull molecules with the general structure DA'A by inserting an additional electron-deficient unit $A^{\prime}$, such as a pyrimidine or a benzothiadiazole. This strategy was highly successful as shown by the PV performance reported for co-evaporated BHJ OSCs with $\mathrm{C}_{70}$ prepared with DA-5 (PCE = $6.4 \%),{ }^{95}$ DA-6 $(P C E=5.81 \%){ }^{96}$ or DA-7 $(P C E=6.8 \%) .{ }^{97}$ More recently Wong, Kim and co-workers described efficient vacuum-deposited ternary OSCs reaching a PCE of 8.02 $\%$, after optimization of the composition and the thickness of the photoactive layer prepared by co-evaporation of $\mathrm{C}_{70}, \mathbf{D A}-\mathbf{6}$ and DA-8 exhibiting a thienothiophene-thiazole segment. ${ }^{98} \mathrm{~A}$ broad absorption over the whole visible spectrum was achieved thanks to the complementary absorption of thin-films of the two donors DA-6 $\left(\lambda_{\max }=670 \mathrm{~nm}\right)$ and DA-8 $\left(\lambda_{\max }=530 \mathrm{~nm}\right)$. Note that in this work, binary OSCs with DA-6 or DA-8 and $\mathrm{C}_{70}$ gave the same PCE of $6.52 \%$. 
In parallel, Forrest et al. thoroughly investigated the PV potential of molecules described by Wong, namely DA-6 and DA-7. After preparing a single junction OSCs based on co-evaporation of DA-6 and $\mathrm{C}_{60}(P C E=5.3 \%)$, further improvement was achieved using the photoactive layer DA-6: $\mathrm{C}_{60}$ as front subcell in a tandem cell $(P C E=10.0 \%)$ and as middle subcell in a triple junction OSC $(P C E=11.1 \%) \cdot{ }^{99}$ Very recently the same group has reported the highest ever reported $P C E$ for an organic solar cell, namely $15.0 \%$ for an organic tandem OSC of $2 \mathrm{~mm}^{2}$ active area, combining vacuum- and solution-processed subcells. ${ }^{100}$ Herein a layer of co-evaporated DA-7 and $\mathrm{C}_{70}$ was used for the front subcell while the back subcell consisted in a blend of donor polymer PCE-10 and ITIC, a nonfullerene acceptor based on indacenodithieno[3,2-b]thiophene, exhibiting both complementary optical properties.

Finally, Mishra, Bäuerle and Sharma and co-workers have recently described a soluble TPA-heteropentacene-DCV DA-9 with a small bandgap of $1.59 \mathrm{eV}$ and prepared BHJ with $\mathrm{PC}_{71} \mathrm{BM}$. The initial PCE of $3.34 \%$ was improved after successive optimizations of the active layer by adding $0.3 \mathrm{vol} \% 1,8$-diiodooctane $(P C E=6.31 \%)$ and thermal annealing $(P C E=7.26 \%) .{ }^{101}$ All these results show that TPA-based linear DA push-pull molecules have progressively acquired a prominent place among other classes of donor materials for OPV. 


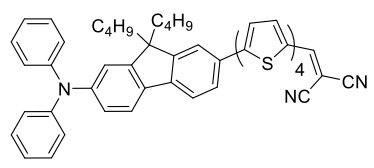

DA-1 $\left(2.67 \%, \mathrm{C}_{60}\right)$

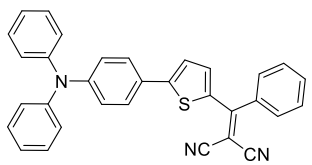

DA-4 $\left(5.11 \%, C_{70}\right)$

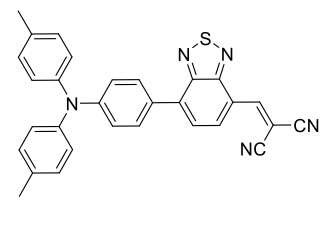

DA-7 $\left(6.8 \%, C_{70}\right)$
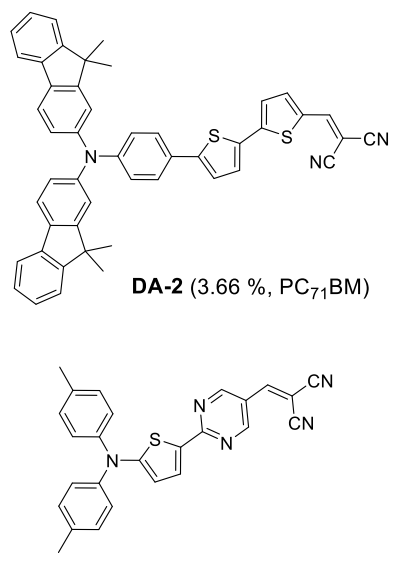

DA-5 $\left(6.4 \%, C_{70}\right)$

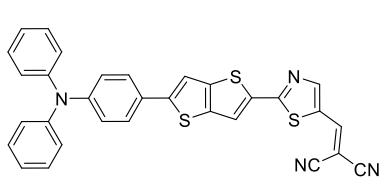

DA-8 $\left(6.52 \%, C_{70}\right)$

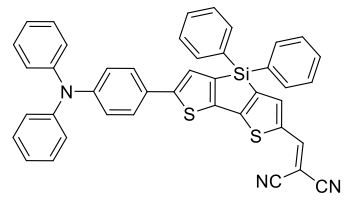

DA-3 $\left(3.82 \%, C_{70}\right)$
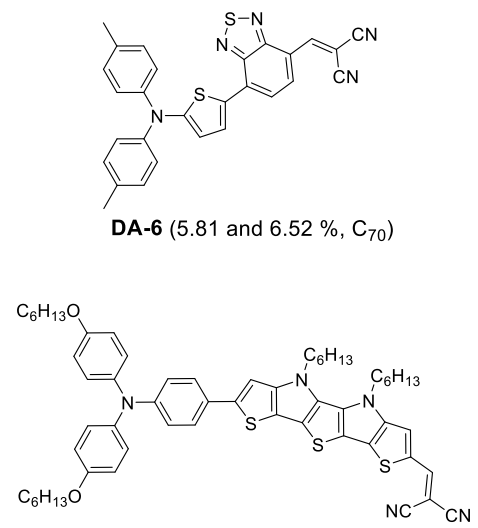

DA-9 (7.26 \%, PC $\left.{ }_{71} \mathrm{BM}\right)$

Scheme 5: Representative examples of TPA-based DA push-pull donors and PCE values of single-junction OSCs

Our group has developed a large number of small linear DA push-pull molecules for OPV since 2009. Owing to the significantly twisted structure of the TCBD derivative DAD-8a, its half structure, namely molecule DA-10, was first investigated for OPV (Figure 9). Initially prepared in only three chemical steps involving a Pd-catalyzed Stille crosscoupling, ${ }^{102,103}$ the synthesis of DA-10 was further optimized by starting from commercial 4-bromotriphenylamine and using a direct $\mathrm{C}-\mathrm{H}$ arylation reaction, avoiding the use of toxic stannyl derivatives, followed by a Knœvenagel condensation. ${ }^{104}$ Thus DA-10 combines a simple, clean and scalable synthesis. The maximum of absorption of DA-10 $\left(\lambda_{\max }=501\right.$ $\mathrm{nm}$ ) in solution is subjected to a $64 \mathrm{~nm}$ hypsochromic shift compared to that of DAD-8a in agreement with the weaker electron-withdrawing character of DCV compared to TCBD. Accordingly, the CV of DA-10 exhibits a reversible one electron oxidation wave peaking at $E_{\mathrm{pa}}{ }^{1}=0.59 \mathrm{~V}$ vs $\mathrm{Fc} / \mathrm{Fc}^{+}$, a value which is slightly shifted towards negative potential 
compared to DAD-8a $\left(E_{\mathrm{pa}}{ }^{1}=0.63 \mathrm{~V}\right)$. This structural change induces also the irreversibility of the reduction wave of DA-10 observed at the same value that the star-shaped molecule $\mathbf{D A}_{3}-\mathbf{1}\left(E_{\mathrm{pr}}{ }^{1}=-1.65 \mathrm{~V}\right)$. Comparison of the electrochemical data of DAD-8a and DA-10 shows clearly that while the HOMO levels are close, the LUMO level of DA-10 is significantly destabilized which can account for the higher HOMO-LUMO gap observed by absorption spectroscopy. Thin-films of DA-10 were easily prepared by solutionprocessing and used to fabricate a bilayer device ITO/PEDOT-PSS/ DA-10/C60/Al with a PCE of $2.53 \%$, a higher value than the ones recorded for $\mathbf{D A}_{3}-\mathbf{1}$ and DAD-8a. ${ }^{61,85}$ This result showed that simplified and size-reduced structures could give rise to easily accessible and efficient molecular donors for OPV.
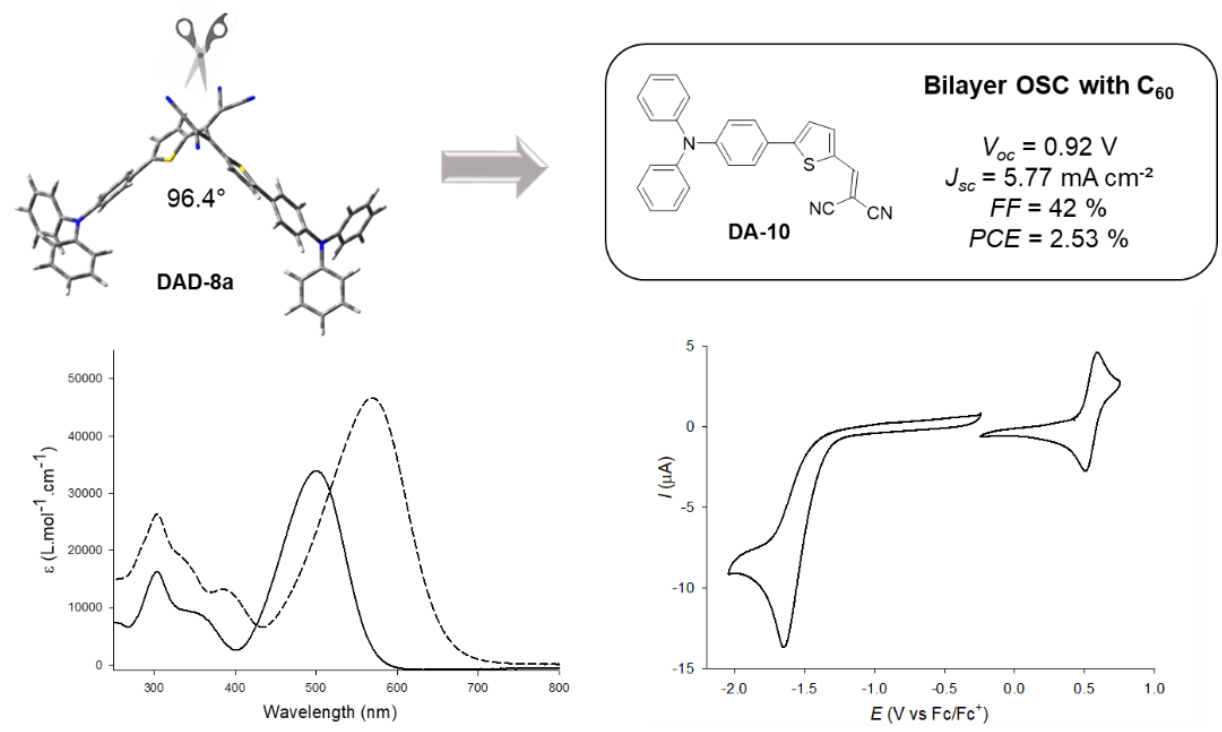

Figure 9: DFT-optimized geometry of DAD-8a (Gaussian 09 B3LYP/6-31G(d,p) level) and structure of DA-10 corresponding to half of DAD-8a and related photovoltaic performance (Top). Absorption spectra of DAD-8a (dashed line) and DA-10 (solid line) in $\mathrm{CH}_{2} \mathrm{Cl}_{2}$ (bottom left) and CV of DA-10 $0.5 \mathrm{mM}$ in $0.1 \mathrm{M} \mathrm{Bu} 4 \mathrm{NPF}_{6} / \mathrm{CH}_{2} \mathrm{Cl}_{2}$, Pt working electrode, scan rate $100 \mathrm{mV} / \mathrm{s}$ (bottom right).

Device optimization by thermal treatment of bilayer OSCs prepared by successive vacuum-deposition of DA-10, using $\mathrm{C}_{70}$ instead of $\mathrm{C}_{60}$ for better absorbing properties in 
the visible spectrum and an additional $\mathrm{Ca}$ interlayer and $\mathrm{Al}$ led to a $P C E$ of $3.70 \% .{ }^{103} \mathrm{An}$ increased PCE of $4 \%$ was obtained in a multi-layer co-evaporated BHJ OSC using DA10 and $C_{60}$, the $V_{o c}$ reaching an exceptionally high value of nearly $1 \mathrm{~V}$ and the relatively high FF value of $64 \%$ was associated with good charge extraction at the electrodes (Figure 10). The hole-transport properties of evaporated thin-films of DA-10 were also analysed by the SCLC method giving a hole mobility of $\mu \mathrm{h}$ of $1.0 \times 10^{-5} \mathrm{~cm}^{2} \mathrm{~V}^{-1} \mathrm{~s}^{-1}{ }^{105}$ Finally solution-processed BHJ OSCs have been tested by mixing compound DA-10 and $\mathrm{PC}_{61} \mathrm{BM}$ leading to $3.0 \%$ efficiency and again a high $V_{\text {oc }}$ value of $1 \mathrm{~V} .{ }^{106}$

\begin{tabular}{|c|}
\hline $\operatorname{Al}(100 \mathrm{~nm})$ \\
\hline $\operatorname{LiF}(1.2 \mathrm{~nm})$ \\
\hline $\mathrm{C}_{60}(30 \mathrm{~nm})$ \\
\hline $12: \mathbf{C}_{60}(70: 30 \ldots 50: 50,30 \mathrm{~nm})$ \\
\hline $12(15 \mathrm{~nm})$ \\
\hline$\alpha$-NPB $(5 \mathrm{~nm})$ \\
\hline PEDOT-PSS $40 \mathrm{~nm})$ \\
\hline ITO \\
\hline
\end{tabular}

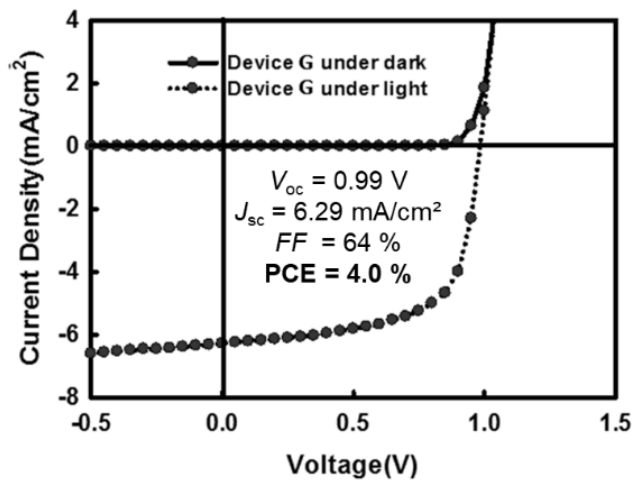

Figure 10: Vacuum-processed BHJ OSC based on DA-10 and current density vs voltage curves under AM 1.5 white light illumination at $100 \mathrm{~mW} / \mathrm{cm}^{2}$. Adapted from ref. 105.

Subtle modifications of the structure of DA-10 were then developed as represented in Scheme 6. Pursuing further the idea of reducing the size of push-pull molecules for OPV, miniaturized systems were synthesized to check their propensity to produce photovoltaic conversion and to use these new platforms for more sophisticated molecules. First, the internal benzene ring of DA-10 was suppressed affording DA-11 with a diphenylthienylamine electron-donating block directly end-capped with a DCV unit. ${ }^{107}$ The 
oxidation peak potential of the first reversible oxidation wave of DA-11 is shifted toward more positive potential $\left(E_{\mathrm{pa}}{ }^{1}=0.78 \mathrm{~V} v s \mathrm{Fc} / \mathrm{Fc}^{+}\right)$. As expected for a less $\pi$-extended system, the absorption maximum in $\mathrm{CH}_{2} \mathrm{Cl}_{2}$ decreases $\left(\lambda_{\max }=473 \mathrm{~nm}\right)$. However, bilayer OSCs (ITO/PEDOT-PSS/DA-11/C60/Al) were successfully fabricated by spin-casting a $\mathrm{CHCl}_{3}$ solution of DA-11 leading to a relatively high PCE of $1.92 \%$ for such a small molecule. A fused-analogue system DA-12 based on a thieno[2,3]indole electrondonating block was later reported. ${ }^{108}$ This compound exhibits a reversible oxidation wave at highly positive potential $E_{\mathrm{pa}}{ }^{1}=0.97 \mathrm{~V}$ and an irreversible reduction wave at $E_{\mathrm{pr}}{ }^{1}=-1.72$ V. The ICT band of DA-12 in $\mathrm{CH}_{2} \mathrm{Cl}_{2}$ decreases down to $452 \mathrm{~nm}$ albeit showing high extinction molar coefficients $\varepsilon$ of $62000 \mathrm{M}^{-1} \mathrm{~cm}^{-1}$. Thin-films of DA-12 prepared by vacuum-evaporation showed relatively good hole-transport properties $\left(\mu_{\mathrm{h}}=2.27 \times 10^{-5}\right.$ $\mathrm{cm}^{2} \mathrm{~V}^{-1} \mathrm{~s}^{-1}$ ) and were used in bilayer OSCs with $\mathrm{C}_{60}$ giving a PCE of $1.06 \%$. This lowmolecular weight compound represents the smallest push-pull molecule ever reported with a $P C E$ higher than $1 \%$, further investigations on more extended push-pull systems are still underway. 


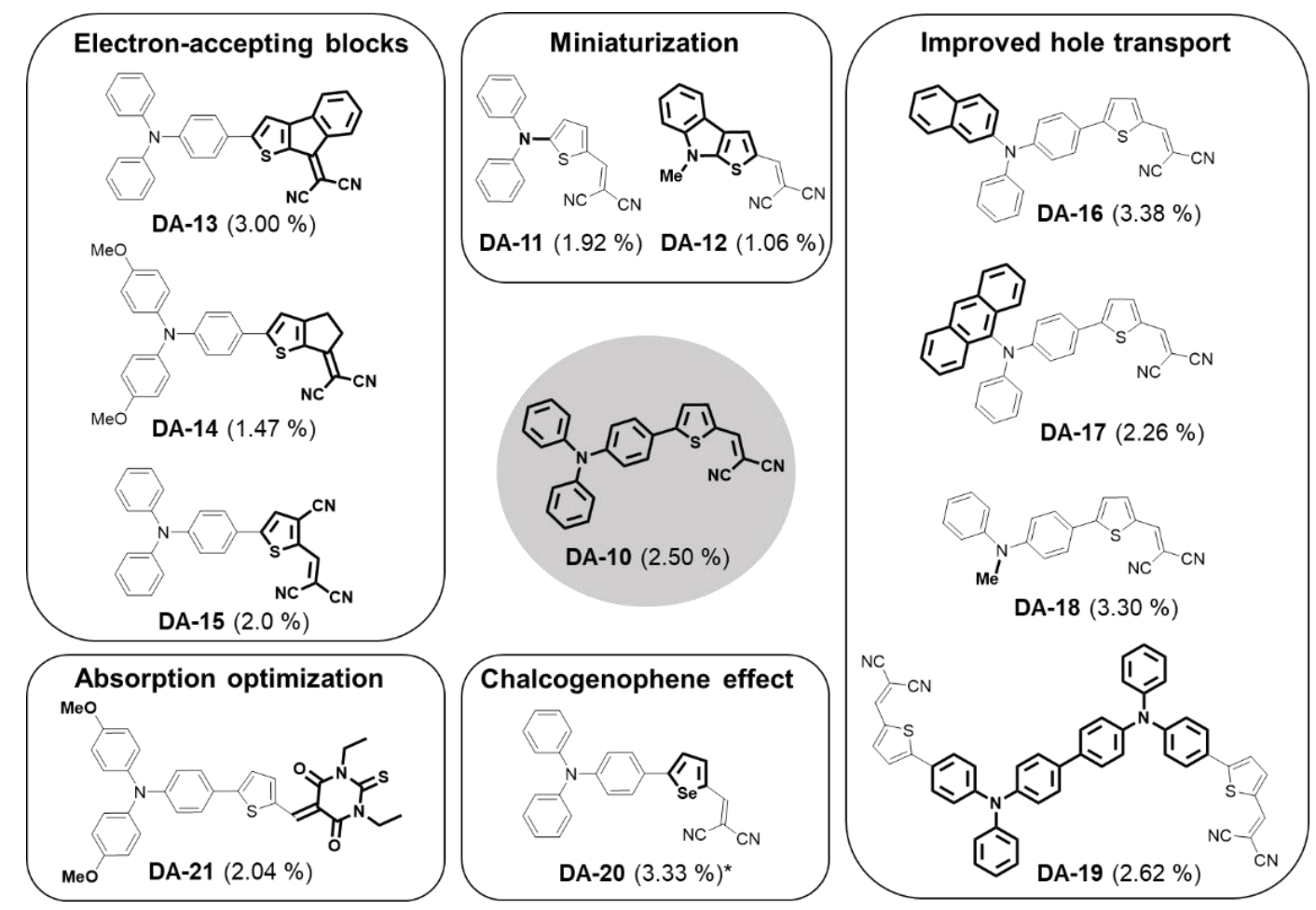

Scheme 6: Examples of structural changes of push-pull donor DA-10 and PCE of related bilayer OSCs with $\mathrm{C}_{60}$ ( ${ }^{*} \mathrm{BHJ}$ OSC with $\left.\mathrm{PC}_{61} \mathrm{BM}\right)$.

Push-pull molecules with new DCV-based electron-accepting blocks were developed by covalent bridging of the DCV terminal unit of DA-10 affording compounds DA-13 ${ }^{102,103}$ and DA-14, ${ }^{109}$ or by introducing an additional nitrile electron-withdrawing in DA-15. ${ }^{104}$ The best PV performance was obtained with compound DA-13 where the DCV group has been fused to the thiophene by a phenyl ring. Compared to DA-10, the structural change in DA-13 induces a significant bathochromic shift of the maximum of absorption of the ICT band from $501 \mathrm{~nm}$ to $610 \mathrm{~nm}$ together with a ca. twofold decrease in the molar absorption coefficient $\varepsilon$ (Figure 11). The bridging of the DCV unit leads to a negligible decrease in $E_{\mathrm{pa}}{ }^{1}(-10 \mathrm{mV})$, but to a large $430 \mathrm{mV}$ positive shift of the reduction wave $\left(E_{\mathrm{pr}}{ }^{1}=-1.22 \mathrm{~V}\right.$ vs $\left.\mathrm{Fc} / \mathrm{Fc}^{+}\right)$. These results show that while the ortho-phenylene bridge has a small influence on the HOMO level, it leads to a significant stabilization of the LUMO 
level demonstrating the strong electron-withdrawing effect of this new electron-accepting group. The full reversibility of the first reduction wave indicating a stabilization of the reduced state, can be interpreted by the formation of an aromatic cyclopentadienyl radical anion upon reduction. Bilayer OSCs prepared by spin-casting a solution of DA-13 and subsequent evaporation of $\mathrm{C}_{60}$ led to a $V_{\mathrm{oc}}$ of $0.97 \mathrm{~V}$, a $\mathrm{Jsc}_{\mathrm{sc}}$ of $5.32 \mathrm{~mA} \mathrm{~cm}^{-2}$ and a FF of $52 \%$ resulting in a PCE of $3.00 \%$. It is worth mentioning that taking advantage of the complementary optical properties of DA-10 and DA-15, a blend of these compounds was used as donor layer in a bilayer OSC with $\mathrm{C}_{60}$ affording a PCE of $3.06 \% .{ }^{104}$
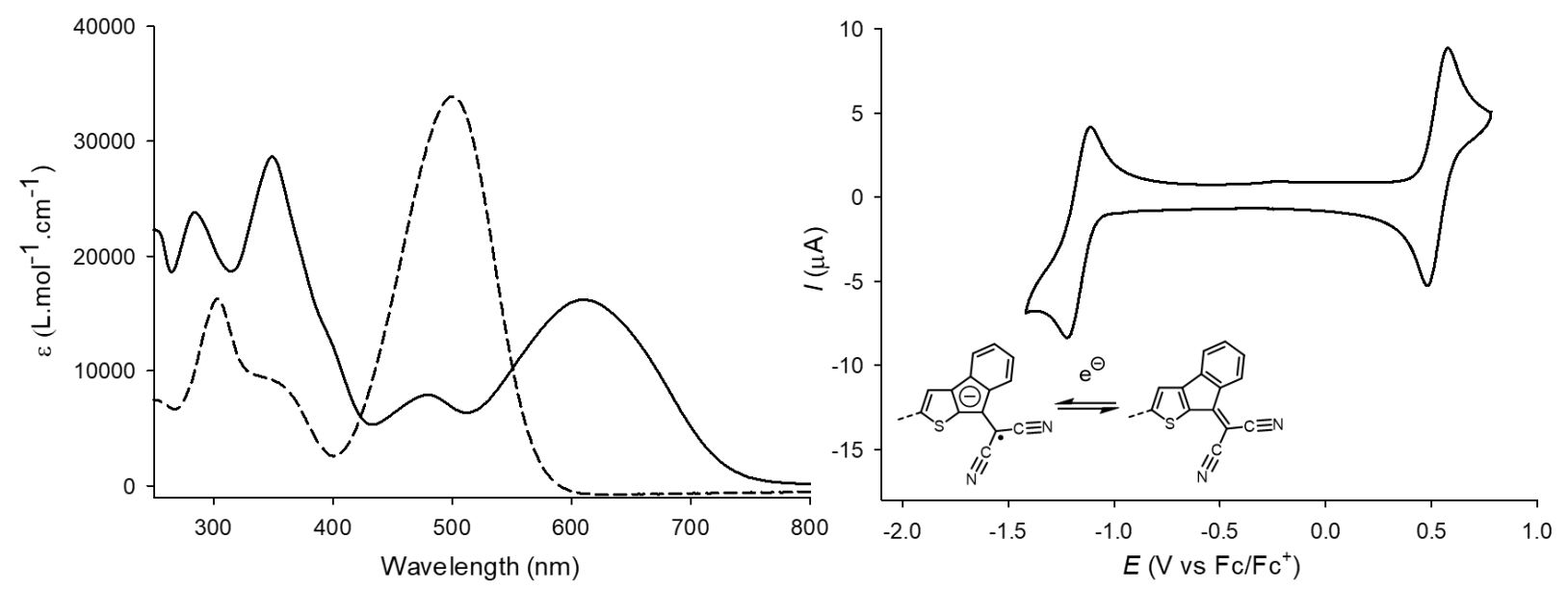

Figure 11: Absorption spectra of DA-10 (dashed line) and DA-13 (solid line) in $\mathrm{CH}_{2} \mathrm{Cl}_{2}$ (Left). CV of DA-13 $1 \mathrm{mM}$ in $0.1 \mathrm{M} \mathrm{Bu}_{4} \mathrm{NPF}_{6} / \mathrm{CH}_{2} \mathrm{Cl}_{2}$, Pt working electrode, scan rate $100 \mathrm{mV} / \mathrm{s}$ and generation of a cyclopentadienyl radical anion upon electrochemical reduction (Right).

One limitation of small molecules compared to conjugated polymers as donor materials for OPV, is their comparatively weaker hole transport properties. Different molecular engineering approaches have been investigated in our group to tackle this problem. First, one of the external phenyl rings of the TPA of DA-10 has been replaced 
by a $\pi$-extended naphthyl platform attached via its $\beta$ position to the nitrogen atom. ${ }^{110}$ Compared to reference DA-10, this structural modification has nearly no consequences on the electrochemical and optical properties of the resulting molecule DA-16 ( $\lambda_{\max }=500$ $\mathrm{nm}, E_{\mathrm{pa}}{ }^{1}=0.58 \mathrm{~V}$ and $\left.E_{\mathrm{pr}}{ }^{1}=-1.63 \mathrm{~V} v \mathrm{Fc} / \mathrm{Fc}^{+}\right)$. However, bilayer OSCs with DA-16 and $\mathrm{C}_{60}$ produce a significant increase of $P C E$ up to $3.38 \%$ particularly due to a large increase of $J_{\mathrm{sc}}\left(7.80 \mathrm{~mA} \mathrm{~cm}^{-2}\right)$ which can be correlated to a parallel increase of hole mobility $\mu \mathrm{h}$. Indeed a value of $\mu \mathrm{h}$ of $5.0 \times 10^{-5} \mathrm{~cm}^{2} \mathrm{~V}^{-1} \mathrm{~s}^{-1}$ was measured on thin-films of DA-16, a five times higher value than the one measured on DA-10 probably due to different intermolecular interactions and molecular packing. Pursuing this approach, one outermost phenyl ring of TPA was recently replaced by a 2- or 9-anthryl group. ${ }^{111}$ Bilayer OSCs were prepared by spin-casting solutions of these compounds and subsequent evaporation of $\mathrm{C}_{60}$. A higher PCE of $2.26 \%$ was measured for the 9-anthryl derivative DA-17 (vs $1.20 \%$ for the 2-anthryl one) due to its better hole transport properties associated to its $3 \mathrm{D}$ structure.

Interestingly when one outermost phenyl of DA-10 is substituted by a methyl group, ${ }^{112}$ again the electrochemical and optical properties of the related molecule DA-18 in solution are nearly identical to those of DA-10. However, analysis of single crystals by X-ray diffraction shows a head-to-tail molecular packing for $\mathbf{D A - 1 0 ,}{ }^{103}$ as very often observed for strongly dipolar push-pull molecules, whereas the crystalline structure of DA18 exhibits a completely different co-facial arrangement. ${ }^{112}$ Furthermore, the optical bandgaps determined on thin-films of DA-10 $\left(E_{g}=2.00 \mathrm{eV}\right)$ and DA-18 differ significantly. In fact, freshly spin-casted thin-films of DA-18 progressively undergo a red shift with an increase of a new band at $620 \mathrm{~nm}$ and an absorption threshold leading to an estimated bandgap of $E_{g}=1.72 \mathrm{eV}$. These results show that the replacement of a phenyl by a methyl 
substituent strongly affects the molecular organization in the solid state. In addition a fiftyfold increase of $\mu \mathrm{h}\left(5.0 \times 10^{-4} \mathrm{~cm}^{2} \mathrm{~V}^{-1} \mathrm{~s}^{-1}\right)$ was measured for DA-18 as compared with DA10, which is consistent with a more effective molecular packing. Owing to these good absorption and hole transport properties, PV performance was improved in bilayer OSCs fabricated either by spin-casting or evaporation of DA-18 leading to PCE of $2.92 \%$ and $3.30 \%$, respectively. ${ }^{112} \mathrm{~A}$ recent theoretical investigation on the effect of the substitution of one outermost phenyl ring of DA-10 by a naphthyl (DA-16) or a methyl (DA-18) group confirmed that although the effects of the substituents on the electronic and optical properties are negligible, they have an impact on the molecular packing of the crystalline structure. In particular, the methyl substituent favours a face-to-face $\pi-\pi$ packing in the crystal structure improving the transport properties. ${ }^{113}$

It is worth mentioning that a bilayer OSC with the ADA push-pull molecule DA-19 and $\mathrm{C}_{60}$ gave a $P C E$ value of $2.62 \%$ and a high $\mathrm{Jsc}_{\mathrm{sc}}$ value of $8.41 \mathrm{~mA} \mathrm{~cm}-2 .{ }^{114}$ Although hole-mobility measurements were not performed on thin-films of DA-19, it is likely that the preceding PV parameters can be related to good hole transport properties which may be related to the presence of a central TPB unit known to favor hole transport. This dimeric analogue of DA-10 shows a red shifted ICT band with a maximum at $529 \mathrm{~nm}$, whereas the replacement of a TPA unit by a TPB one leads to two one-electron reversible waves at $0.44 \mathrm{~V}$ and $0.63 \mathrm{~V} v s \mathrm{Fc} / \mathrm{Fc}^{+}$, the negative shift of the first oxidation wave induces a decrease of $V_{o c}(0.63 \mathrm{~V})$.

The effect of the nature of the chalcogenophene $\pi$-connector in DA-10 on its electronic properties and PV performance has been investigated. ${ }^{106}$ Replacement of furane by thiophene and selenophene leads to a progressive decrease of the optical band gap of the material and to a parallel increase of hole mobility and PCE. Thus, a PCE of 
$3.33 \%$ has been obtained for a simple air- and solution-processed $\mathrm{BHJ}$ involving the selenophene-based donor DA-20 and $\mathrm{PC}_{61} \mathrm{BM}$. On the other hand, structural modulation of the ICT band from $519 \mathrm{~nm}$ to $707 \mathrm{~nm}$ was achieved in push-pull molecules terminated by a stronger dianisylamino electron-donating block using different $\pi$-conjugating spacers and various terminal electron-deficient groups. ${ }^{115}$ The use of the dianisylamino group leads to a reversible oxidation wave with lower oxidation potentials values. For instance, the thiobarbituric acid derivative DA-21 exhibits a $E_{\mathrm{pa}}{ }^{1}$ value of $0.29 \mathrm{~V} v s \mathrm{Fc} / \mathrm{Fc}^{+}$. The best bilayer OSC with this TPA-based compound DA-21 gave a PCE of $2.04 \%$ although the $V_{\text {oc }}$ value of $0.59 \mathrm{~V}$ is relatively low due to the too strong electron-donating character of the dianisylamino group.

More recently, in order to explore the potential of multimers $(D A)_{n}$ of DA push-pull molecules for OPV, we prepared Tetra-T and Tetra-CPDT, two tetramers of TPA-based DA push-pull molecules linked by a non-conjugated central pentaerythritol $\sigma$-linker ( Figure 12). ${ }^{116}$ The two push-pull moieties differ by the presence of a simple thiophene (T) or a more $\pi$-extended cyclopentadithiophene (CPDT) as $\pi$-spacer between the TPA and a cyanoacrylic ester group. The tetramer based on CPDT exhibits an ICT band at longer wavelength than the thiophene analogue in solution, respectively $\lambda_{\max }=533 \mathrm{~nm}$ and 490 $\mathrm{nm}$. While the Tetra-T is characterized by one reversible oxidation wave at a $E_{\mathrm{pa}}{ }^{1}$ value of $0.59 \mathrm{~V} v s \mathrm{Fc} / \mathrm{Fc}^{+}$leading to a tetra(radical cation) species, its CPDT counterpart exhibits two reversible oxidation waves peaking at $0.39 \mathrm{~V}$ and $0.73 \mathrm{~V}$, respectively assigned to the formation of a stable radical cation and a dication per independent push-pull unit. When blended with $\mathrm{PC}_{71} \mathrm{BM}$ in BHJ OSCs, Tetra-T and Tetra-CPDT led to the promising PCEs of $4.5 \%$. The $V_{\text {oc }}$ value for Tetra-CPDT appears slightly lower than that of Tetra-T (0.88 $\mathrm{V} v s 0.93 \mathrm{~V}$ ) in agreement with its lower oxidation potential whereas the $\mathrm{Jsc}_{\mathrm{sc}}$ value for Tetra- 
CPDT is slightly increased ( $12.93 \mathrm{~mA} \mathrm{~cm}^{-2}$ vs $\left.12.43 \mathrm{~mA} \mathrm{~cm}^{-2}\right)$ owing to its better absorption properties. This approach based on multimers of push-pull molecules opens interesting perspectives for the design of new materials for OPV.
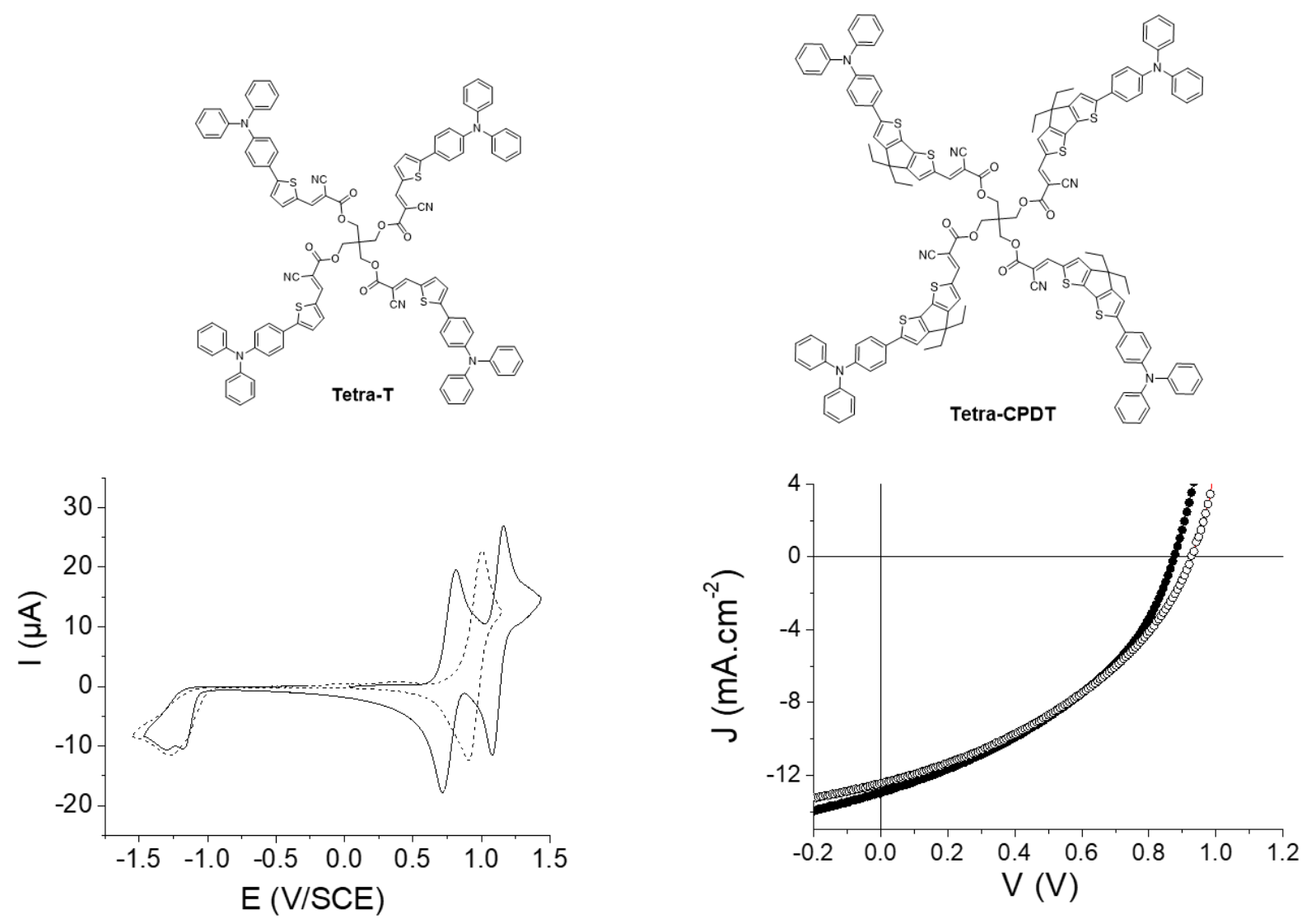

Figure 12: $\mathrm{CV}$ of Tetra-T (dashed line) and Tetra-CPDT (solid line) $0.5 \mathrm{mM}$ in $0.1 \mathrm{M}$ $\mathrm{Bu}_{4} \mathrm{NPF}_{6} / \mathrm{CH}_{2} \mathrm{Cl}_{2}$, Pt working electrode, scan rate $100 \mathrm{mV} / \mathrm{s}$ and current density vs voltage curves of BHJ OSCs prepared from Tetra-T (white circles) and Tetra-CPDT (black circles) under AM 1.5 white light illumination at $100 \mathrm{~mW} / \mathrm{cm}^{2}$. Adapted from reference 116 by permission of The Royal Society of Chemistry.

Organic materials where the donor and the acceptor components are covalently linked through a nonconjugated $\sigma$-connector have been previously explored for the fabrication of single-component organic solar cells (SC-OSCs). ${ }^{117,118}$ Compared to BHJ, the photoactive layer of SC-OSCs is expected to be less subjected to morphology evolution. In addition, owing to the close proximity of the donor and acceptor components, exciton dissociation on the same molecule may avoid the limiting step of exciton diffusion 
associated with organic semiconductors. However PV performance of SC-OSCs are still lower than those of BHJ OSCs and most materials evaluated in SC-OSCs led to PCE values often much below $0.5 \%$. However SC-OSCs using discrete molecules such as a dithiafulvalene-functionalized diketopyrrolopyrrole- $\mathrm{C}_{60} \mathrm{dyad}^{119}$ and a triad based on an oligothiophene-fullerene conjugate ${ }^{120}$ have recently led to encouraging PCEs of $2.2 \%$ and $2.4 \%$, respectively.

In this context, our group has recently reported the synthesis of TPA-T-C 60 , a TPAbased DA push-pull- $\sigma-\mathrm{C}_{60}$ dyad. ${ }^{121}$ The latter shows a broad ICT band at $478 \mathrm{~nm}$ characteristic of the push-pull moiety and the presence of specific absorption bands at 259 and $327 \mathrm{~nm}$, together with a discernible band at $431 \mathrm{~nm}$ characteristic of the fullerene unit (Figure 13). Also the CV of TPA-T- $\mathbf{C}_{60}$ exhibits both the electrochemical signatures of the push-pull moiety and $\mathrm{PC}_{61} \mathrm{BM}$. Thus, the reversible oxidation wave at $E_{\mathrm{pa}}{ }^{1}=0.57 \mathrm{~V}$ and the irreversible reduction wave at $E_{\mathrm{pr}}{ }^{3}=-1.69 \mathrm{~V} v \mathrm{Fc} / \mathrm{Fc}^{+}$are associated to the formation of the radical cation and radical anion of the push-pull moiety while the two first reversible reduction waves at $E_{\mathrm{pr}}{ }^{1}=-1.15 \mathrm{~V}$ and $E_{\mathrm{pr}^{2}}=-1.53 \mathrm{~V} v s \mathrm{Fc} / \mathrm{Fc}^{+}$correspond to the stable radical anion and dianion of the fullerene unit (Figure 13). Spectroelectrochemical analysis revealed the optical signatures of the radical cation of the push-pull moiety and the radical anion of the fullerene unit. The former one mainly exhibits two strong broad absorption bands peaking at 610 and $1033 \mathrm{~nm}$ whereas the latter one is characterized by a weak band at $1030 \mathrm{~nm}$. SCLC measurements gave an electron mobility of $\mu_{\mathrm{e}}=4.3 \times 10^{-4} \mathrm{~cm}^{2} \mathrm{~V}^{-1} \mathrm{~s}^{-1}$, ca. 50 times higher than the hole mobility. SC-OSCs with the following structure ITO/PEDOT-PSS/TPA-T-C60/Ca/Al were characterized by an open-circuit voltage $V_{o c}$ of $0.73 \mathrm{~V}$, a short-circuit current density of $2.1 \mathrm{~mA} \mathrm{~cm}^{-2}$, a poor fill factor $F F$ of $29 \%$, overall resulting in a PCE of $0.4 \%$. Transient 
absorption spectroscopy time delayed collection field experiments confirmed that photoexcitation of a thin-film of TPA-T-C 60 led to an ultrafast and efficient charge generation and showed the presence of pure fullerene domains. However, the fast recombination competes with the extraction of separated charges hence giving rise to SCOSCs with relatively poor PV performance. Nevertheless, these results reveal that charge percolation is possible in these devices and that new molecular dyads with self-assembly properties for optimized nanophase separation could be of interest.
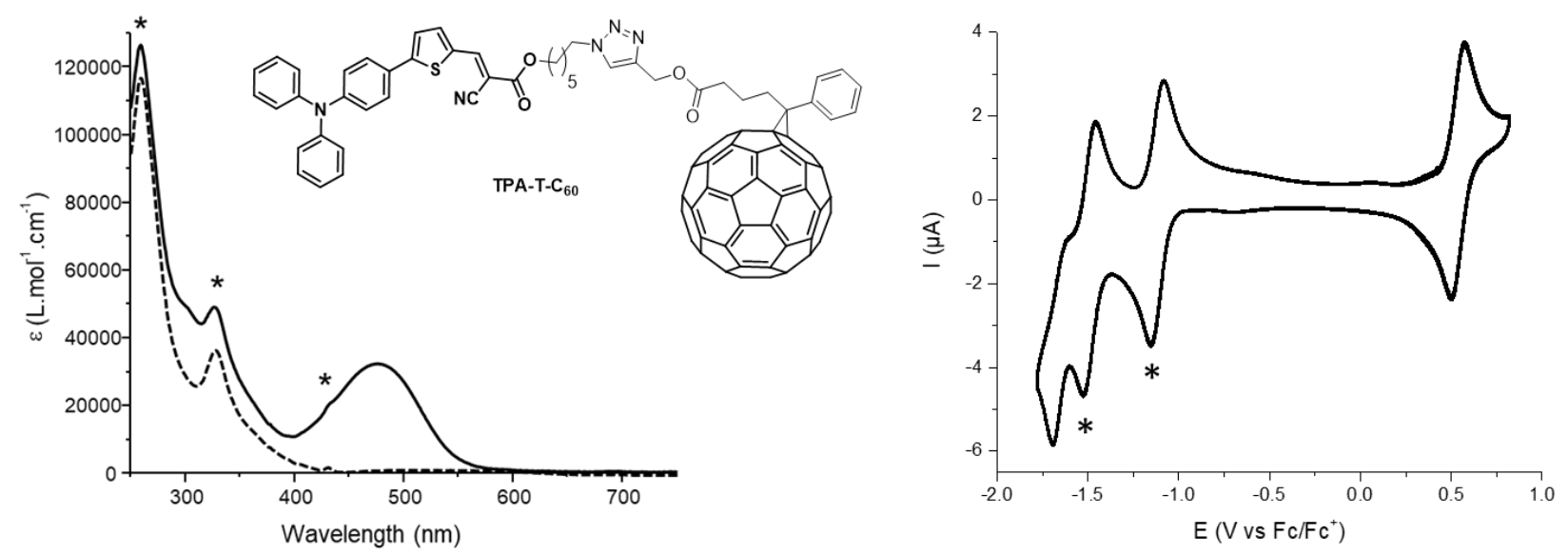

Figure 13: Structure of TPA-T- $\mathbf{C}_{60}$, UV-vis spectra of TPA-T- $\mathbf{C}_{60}$ (solid line) and PC $_{61} B M$ (dashed line) in $\mathrm{CH}_{2} \mathrm{Cl}_{2}$ and $\mathrm{CV}$ of TPA-T- $\mathrm{C}_{60}$ in $0.1 \mathrm{M} \mathrm{Bu}_{4} \mathrm{NPF}_{6} / \mathrm{CH}_{2} \mathrm{Cl}_{2}$, Pt working electrode, scan rate $100 \mathrm{mV} / \mathrm{s}$. The stars highlight the electrochemical and optical signatures of the fullerene moiety of TPA-T-C 60. Adapted from ref. 121.

\section{Conclusion}

Owing to their relative ease of synthesis and their adapted electronic properties that can be finely tuned by known synthetic reactions, triphenylamine and its derivatives represent excellent building blocks for the preparation of electroactive materials for optoelectronic devices. A number of TPA-based amorphous materials have been used as hole 
transporting/injection layer in OLEDs, field-effect transistors or OSCs. On the other hand, push-pull molecules based on TPA constitute outstanding photoactive donor materials for OSCs. This article has given an overview of this important class of materials highlighting the relation between their structure and their optical and electrochemical properties and additionally their photovoltaic performances. In particular, simple and cost-effective linear TPA-based DA push-pull molecules have led to solution or vacuum-processed single junction OSCs showing power conversion efficiencies as high as $8 \%$. Moreover, very recent works from the literature have demonstrated that simple DA push-pull systems can be implemented in tandem or triple junction OSCs with record efficiencies up to $15 \%$ hence stimulating further research. As illustrated in this review, the group of Angers has investigated a large number of small, efficient and scalable push-pull molecules for OPV following different molecular engineering approaches. While new small push-pull molecules are still under investigation, the recent development of easily accessible multimers of push-pull molecules could represent an interesting perspective for OPV.

From an electrochemistry and polymer science viewpoint, the propensity of some TPA derivatives to lead to unstable radical cations upon (electro)chemical oxidation and subsequent couplings, has been discussed and particularly exploited by the group of Stuttgart for the synthesis of crosslinked electroactive polymer films. As main methods insitu spectroelectrochemistry of solutions and films and cyclic voltammetry coupled with in situ conductance measurements have been applied to study mechanisms and identify the generated redox species.

Our strategy of chemically synthesizing tailor-made polymers and block copolymers, solution processing them into film architectures and subsequently inducing 
the crosslinking reaction or post-polymerization is particularly relevant for applications in organic electronics and nanotechnology applications.

In the case of a PSTPA, well resolved conductivity regimes could be identified which were explained by mixed valence conductivity, as is characteristic for redox polymers. Especially the possibility to chemically synthesize tailor-made block copolymers from PSTPA and a soft-degradable polymer block such as poly(lactide) are highly attractive for the preparation of electroactive nanoporous templates.

Attaching TPA further to conjugated regioregular polythiophene backbones yields conjugated redox polymers which after electrochemical crosslinking lead to stable highly conducting polymer films. Learning from electrochemistry we have transferred the crosslinking reaction to occur in an analogous way with chemical dopants as proven by four point probe measurements yielding conductivities as high as $8 \mathrm{~S} / \mathrm{cm}$. Highly conducting polymer films which are additionally reasonably transparent will be further exploited as hole transport layers in solar cells and future alternative applications will include thermoelectric devices.

\section{Acknowledgments}

We thank Prof. J. Heinze, Prof. U. Steiner, Prof. M. Hillmyer, Dr. O. Yurchenko, Dr. E.J.W. Crossland, P. Reinold and K. Bruchlos for their highly valuable contributions to the respective studies. Financial support was given by the German Science Foundation within an Emmy Noether Grant. We thank all the PhD and postdoctoral students involved in the OPV projects. Colleagues from MOLTECH-Anjou, Dr. A. Cravino, Prof. P. Leriche, Pr. P. Frère, Dr. F. Gohier, Dr. O. Segut, Dr. O. Alévêque, Dr. J-C. Bernède and Dr. L. Sanguinet are acknowledged for their contributions as well as collaborators Dr. D. Tondelier from Ecole Polytechnique, Palaiseau (France), Dr. B. Geffroy from CEA Saclay (France) and Prof. F. Laquai and Dr. J. Gorenflot from King Abdullah University of Science and Technology (Saudi Arabia). 


\section{References}

1. Shirota Y, J Mater Chem 10:1-25 (2000)

2. Degli Esposti A, Fattori V, Sabatini C, Casalbore-Miceli G, Marconi G, Phys Chem Chem Phys 7:3738-3743 (2005)

3. Shirota Y, Kageyama H, Chem Rev 107:953-1010 (2007)

4. Cias P, Slugovc C, Gescheidt G, J Phys Chem A 115:14519-14525 (2011)

5. Thelakkat M, Macromol Mater Eng 287:442-461 (2002)

6. Rybakiewicz R, Zagorska M, Pron A, Chem Pap 71:243-268 (2017)

7. Bellmann E, Shaheen SE, Thayumanavan S, et al., Chem Mater 10:1668-1676 (1998)

8. Kwak J, Bae WK, Zorn M, et al., Adv Mater 21:5022-5026 (2009)

9. Chou MY, Leung MK, Su YO, et al., Chem Mater 16:654-661 (2004)

10. Roncali J, Leriche P, Blanchard P, Adv Mater 26:3821-3838 (2014)

11. Malytskyi V, Simon J-J, Patrone L, Raimundo J-M, RSC Adv 5:354-397 (2015)

12. Wang J, Liu K, Ma L, Zhan X, Chem Rev 116:14675-14725 (2016)

13. Ning Z, Tian H, Chem Commun 0:5483-5495 (2009)

14. Agarwala P, Kabra D, J Mater Chem A 5:1348-1373 (2017)

15. Su C, Yang F, Ji L, Xu L, Zhang C, J Mater Chem A 2:20083-20088 (2014)

16. Zhuang H, Zhou Q, Zhang Q, et al., J Mater Chem C 3:416-422 (2015)

17. Wu J-H, Liou G-S, ACS Appl Mater Interfaces 7:15988-15994 (2015) 
18. Paine AJ, J Am Chem Soc 109:1496-1502 (1987)

19. Manifar T, Rohani S, Can J Chem Eng 82:323-334 (2004)

20. Driver MS, Hartwig JF, J Am Chem Soc 118:7217-7218 (1996)

21. Wolfe, John P, Wagaw S, Buchwald SL, J Am Chem Soc 118:7215-7216 (1996)

22. Hatakeyama T, Imayoshi R, Yoshimoto Y, et al., J Am Chem Soc 134:20262-20265 (2012)

23. Munshi MU, Berden G, Martens J, Oomens J, Phys Chem Chem Phys 19:19881-19889 (2017)

24. Reva I, Lapinski L, Chattopadhyay N, Fausto R, Phys Chem Chem Phys 5:3844-3850 (2003)

25. Wang BC, Liao HR, Chang JC, Chen L, Yeh JT, J Lumin 124:333-342 (2007)

26. Wu J, Wilson BA, Smith Jr. DW, Nielsen SO, J Mater Chem C 2:2591-2599 (2014)

27. Hagberg DP, Marinado T, Karlsson KM, et al., J Org Chem 72:9550-9556 (2007)

28. Pan JH, Chiu HL, Chen L, Wang BC, Comput Mater Sci 38:105-112 (2006)

29. Bender TP, Graham JF, Duff JM, Chem Mater 13:4105-4111 (2001)

30. Seo ET, Nelson RF, Fritsch JM, Marcoux LS, Leedy DW, Adams RN, J Am Chem Soc 88:3498-3503 (1966)

31. Nelson RF, Adams RN, J Am Chem Soc 90:3925-3930 (1968)

32. Creason SC, Wheeler J, Nelson RF, J Org Chem 37:4440-4446 (1972)

33. Nelson RF, Philp RH, J Phys Chem 83:713-716 (1979) 
34. Yurchenko O, Freytag D, Zur Borg L, Zentel R, Heinze J, Ludwigs S, J Phys Chem B 116:30-39 (2012)

35. Sreenath K, Suneesh CV, Ratheesh Kumar VK, Gopidas KR, J Org Chem 73:3245-3251 (2008)

36. Crossland EJW, Cunha P, Scroggins S, et al., ACS Nano 4:962-966 (2010)

37. Heinze J, Frontana-Uribe BA, Ludwigs S, Chem Rev 110:4724-4771 (2010)

38. Barth M, Guilerez S, Bidan G, Bras G, Lapkowski M, Electrochim Acta 45:4409-4417 (2000)

39. Smie A, Synowczyk A, Heinze J, et al., J Electroanal Chem 452:87-95 (1998)

40. Dapperheld S, Steckhan E, Brinkhaus K-HG, Esch T, Chem Ber 124:2557-2567 (1991)

41. Bäuerle P, Adv Mater 4:102-107 (1992)

42. Engelmann G, Kossmehl G, Heinze J, Tschuncky P, Jugelt W, Welzel H-P, J Chem Soc, Perkin Trans 2 0:169-176 (1998)

43. Reynolds R, Line LL, Nelson RF, J Am Chem Soc 96:1087-1092 (1974)

44. Yurchenko O, Heinze J, Ludwigs S, ChemPhysChem 11:1637-1640 (2010)

45. Choi K, Yoo SJ, Sung Y-E, Zentel R, Chem Mater 18:5823-5825 (2006)

46. Sommer M, Lindner SM, Thelakkat M, Adv Funct Mater 17:1493-1500 (2007)

47. Kang HA, Bronstein HE, Swager TM, Macromolecules 41:5540-5547 (2008)

48. Jiang G, Huang C, Baba A, Advincula R, Macromol React Eng 6:153-159 (2012)

49. Torrance JB, Acc Chem Res 12:79-86 (1979) 
50. Chidsey CED, Murray RW, J Phys Chem 90:1479-1484 (1986)

51. John H, Bauer R, Espindola P, Sonar P, Heinze J, Müllen K, Angew Chemie - Int Ed 44:2447-2451 (2005)

52. Crossland EJW, Nedelcu M, Ducati C, et al., Nano Lett 9:2813-2819 (2009)

53. Crossland EJW, Kamperman M, Nedelcu M, et al., Nano Lett 9:2807-2812 (2009)

54. Zalusky AS, Olayo-Valles R, Wolf JH, Hillmyer MA, J Am Chem Soc 124:12761-12773 (2002)

55. Cummins C, Mokarian-Tabari P, Holmes JD, Morris MA, J Appl Polym Sci 131:40798 (2014)

56. Whiting GL, Snaith HJ, Khodabakhsh S, et al., Nano Lett 6:573-578 (2006)

57. Reinold P, Bruchlos K, Ludwigs S, Polym Chem 8:7351-7359 (2017)

58. Yamamoto J, Furukawa Y, J Phys Chem B 119:4788-4794 (2015)

59. Su C, Ye Y, Xu L, Zhang C, J Mater Chem 22:22658-22662 (2012)

60. Roquet S, Cravino A, Leriche P, Alévêque O, Frère P, Roncali J, J Am Chem Soc 128:3459-3466 (2006)

61. Cravino A, Leriche P, Alévêque O, Roquet S, Roncali J, Adv Mater 18:3033-3037 (2006)

62. Leriche P, Frère P, Cravino A, Alévêque O, Roncali J, J Org Chem 72:8332-8336 (2007)

63. Ripaud E, Rousseau T, Leriche P, Roncali J, Adv Energy Mater 1:540-545 (2011)

64. Bernède JC, Cattin L, Makha M, et al., Sol Energy Mater Sol Cells 110:107-114 (2013)

65. Min J, Luponosov YN, Baran D, et al., J Mater Chem A 2:16135-16147 (2014) 
66. Min J, Luponosov YN, Gerl A, et al., Adv Energy Mater 4:1301234 (2014)

67. Shang H, Fan H, Liu Y, Hu W, Li Y, Zhan X, Adv Mater 23:1554-1557 (2011)

68. Cho N, Paek S, Jeon J, Song K, Sharma GD, Ko J, J Mater Chem A 2:12368 (2014)

69. Aytun T, Santos PJ, Bruns CJ, et al., J Phys Chem C 120:3602-3611 (2016)

70. Paek S, Cho N, Cho S, Lee JK, Ko J, Org Lett 14:6326-6329 (2012)

71. Paek S, Choi H, Sim J, Song K, Lee JK, Ko J, J Phys Chem C 118:27193-27200 (2014)

72. Lim K, Lee SY, Song K, et al., J Mater Chem C 2:8412-8422 (2014)

73. Fang Z, Teo TL, Cai L, Lal YH, Samoc A, Samoc M, Org Lett 11:1-4 (2009)

74. Fang Z, Chellappan V, Webster RD, et al., J Mater Chem 22:15397 (2012)

75. Wang X, Zheng X, Wang X, et al., J Am Chem Soc 135:14912-14915 (2013)

76. Zhang J, Wu G, He C, Deng D, Li Y, J Mater Chem 21:3768 (2011)

77. Lin Y, Cheng P, Liu Y, et al., Sol Energy Mater Sol Cells 99:301-307 (2012)

78. $\quad$ Cheng P, Shi Q, Lin Y, Li Y, Zhan X, Org Electron 14:599-606 (2013)

79. Zeng S, Yin L, Ji C, et al., Chem Commun 48:10627 (2012)

80. $\quad$ Wang L, Yin L, Ji C, Li Y, Dye Pigm 118:37-44 (2015)

81. Chi LC, Chen HF, Hung WY, et al., Sol Energy Mater Sol Cells 109:33-39 (2013)

82. Wang S, Hall L, Diev V V., et al., Chem Mater 23:4789-4798 (2011)

83. Wei G, Xiao X, Wang S, et al., ACS Nano 6:972-978 (2012)

84. Kumar CV, Cabau L, Koukaras EN, Sharma GD, Palomares E, Org Electron 26:36-47 
(2015)

85. Leliège A, Blanchard P, Rousseau T, Roncali J, Org Lett 13:3098-3101 (2011)

86. Wu X, Wu J, Liu Y, Jen AK, J Am Chem Soc 121:2391-2392 (1999)

87. Kato S, Diederich F, Chem Commun 46:1994 (2010)

88. Po R, Roncali J, J Mater Chem C 4:3677-3685 (2016)

89. Jeux V, Segut O, Demeter D, et al., Dye Pigm 113:402-408 (2015)

90. Faurie A, Grolleau J, Gohier F, Allain M, Legoupy S, Frère P, Eur J Org Chem 2017:2707$2714(2017)$

91. Xia PF, Feng XJ, Lu J, et al., Adv Mater 20:4810-4815 (2008)

92. Ko HM, Choi H, Paek S, et al., J Mater Chem 21:7248 (2011)

93. Lin H-W, Lin L-Y, Chen Y-H, et al., Chem Commun 47:7872 (2011)

94. Kozlov O V., Luponosov YN, Solodukhin AN, et al., Org Electron 53:185-190 (2018)

95. Chiu S-W, Lin L-Y, Lin H-W, et al., Chem Commun 48:1857-1859 (2012)

96. Lin LY, Chen YH, Huang ZY, et al., J Am Chem Soc 133:15822-15825 (2011)

97. Chen YH, Lin LY, Lu CW, et al., J Am Chem Soc 134:13616-13623 (2012)

98. Shim HS, Moon CK, Kim J, et al., ACS Appl Mater Interfaces 8:1214-1219 (2016)

99. Che X, Xiao X, Zimmerman JD, Fan D, Forrest SR, Adv Energy Mater 4:1400568 (2014)

100. Che X, Li Y, Qu Y, Forrest SR, Nat Energy 3:422-427 (2018)

101. Mishra A, Wetzel C, Singhal R, Sharma GD, J Phys Chem C 112:11262-11269 (2018) 
102. Leliège A, Régent C-H Le, Allain M, Blanchard P, Roncali J, Chem Commun 48:89078909 (2012)

103. Leliège A, Grolleau J, Allain M, et al., Chem Eur J 19:9948-9960 (2013)

104. Grolleau J, Gohier F, Allain M, Legoupy S, Cabanetos C, Frère P, Org Electron 42:322$328(2017)$

105. Choi JW, Kim C-H, Pison J, et al., RSC Adv 4:5236-5242 (2014)

106. Labrunie A, Jiang Y, Baert F, et al., RSC Adv 5:102550-102554 (2015)

107. Jeux V, Demeter D, Leriche P, Roncali J, RSC Adv 3:5811-5814 (2013)

108. Baert F, Cabanetos C, Allain M, Silvestre V, Leriche P, Blanchard P, Org Lett 18:1582$1585(2016)$

109. Demeter D, Jeux V, Leriche P, et al., Adv Funct Mater 23:4854-4861 (2013)

110. Mohamed S, Demeter D, Laffitte JA, Blanchard P, Roncali J, Sci Rep 5:9031 (2015)

111. Jiang Y, Cabanetos C, Jungsuttiwong S, Alberga D, Adamo C, Roncali J, ChemistrySelect 2:6296-6303 (2017)

112. Jiang Y, Cabanetos C, Allain M, Liu P, Roncali J, J Mater Chem C 3:5145-5151 (2015)

113. Alberga D, Ciofini I, Mangiatordi GF, et al., Chem Mater 29:273-281 (2017)

114. Diac A, Demeter D, Jungsuttiwong S, Grosu I, Roncali J, Tetrahedron Lett 56:4607-4612 (2015)

115. Jeux V, Segut O, Demeter D, Alévêque O, Leriche P, Roncali J, Chempluschem 80:697$703(2015)$

116. Labrunie A, Josse P, Dabos-Seignon S, Blanchard P, Cabanetos C, Sustain Energy Fuels 
1:1921-1927 (2017)

117. Segura JL, Martín N, Guldi DM, Chem Soc Rev 34:31-47 (2005)

118. Roncali J, Adv Energy Mater 1:147-160 (2011)

119. Narayanaswamy K, Venkateswararao A, Nagarjuna P, et al., Angew Chemie - Int Ed 55:12334-12337 (2016)

120. Nguyen TL, Lee TH, Gautam B, et al., Adv Funct Mater 27:1702474 (2017)

121. Labrunie A, Gorenflot J, Babics M, et al., Chem Mater 30:3474-3485 (2018) 
Table 1: HOMO, LUMO energies, ionization potentials $\left(I_{p}\right)$ for different tri-para-substituted TPA derivatives obtained from DFT calculations. Data extracted from reference 4.

\begin{tabular}{|c|c|c|c|c|}
\hline $\mathbf{R}$ & $\begin{array}{c}\text { HOMO energy } \\
(\mathbf{e V})\end{array}$ & $\begin{array}{c}\text { LUMO energy } \\
(\mathbf{e V})\end{array}$ & $\begin{array}{c}\Delta \mathrm{E}(\mathrm{H}-\mathrm{L}) \\
(\mathrm{eV})\end{array}$ & $\begin{array}{c}\mathbf{I}_{\mathbf{p}} \\
(\mathrm{eV})\end{array}$ \\
\hline$-\mathrm{H}$ & -5.188 & -0.720 & 4.468 & 6.608 \\
\hline$-\mathrm{NH}_{2}$ & -4.247 & -0.451 & 3.796 & 5.569 \\
\hline$-\mathrm{OCH}_{3}$ & -4.649 & -0.645 & 4.004 & 5.961 \\
\hline$-\mathrm{CH}_{3}$ & -4.925 & -0.629 & 4.296 & 6.265 \\
\hline$-\mathrm{Cl}$ & -5.572 & -1.290 & 4.282 & 6.891 \\
\hline$-\mathrm{CN}$ & -6.420 & -2.345 & 4.075 & 7.696 \\
\hline$-\mathrm{NO}_{2}$ & -6.740 & -3.228 & 3.512 & 8.036 \\
\hline
\end{tabular}

Table 2: Characteristic absorption bands and potentials for TPA, TPB and $p$-TTA and associated redox species upon electrochemical oxidation. ${ }^{34}$

\begin{tabular}{|c|c|c|c|c|c|}
\hline & \multicolumn{3}{|c|}{$\lambda_{\max }[\mathrm{nm}]$} & \multicolumn{2}{c|}{ Electrochemical potential } \\
\hline Species & Neutral & Radical cation & Dication & $\begin{array}{c}\mathrm{E}_{\text {ox,I }}^{\mathrm{p}} \\
{[\text { V vs Fc|Fc+] }}\end{array}$ & $\begin{array}{c}\mathrm{E}_{\text {ox,I }}^{1 / 2} \\
\text { [V vs Fc|Fc+] }\end{array}$ \\
\hline TPA & 302 & $340 ; 562 ; 658$ & - & 0.69 & - \\
\hline TPB & 352 & 484 & 722,450 & 0.35 & 0.25 \\
\hline$p$-TTA & 365 & $365 ; 589 ; 675$ & - & 0.45 & 0.31 \\
\hline
\end{tabular}

